\title{
Alterations in Body Temperature, Corticosterone, and Behavior Following the Administration of 5-Methoxy-Diisopropyltryptamine ('Foxy') to Adult Rats: a New Drug of Abuse
}

\author{
Michael T Williams*, 1,4, Nicole R Herring ${ }^{1,4}$, Tori L Schaefer', Matthew R Skelton', Nicholas G Campbell', \\ Jack W Lipton ${ }^{2}$, Anne E McCrea ${ }^{3}$ and Charles V Vorhees' \\ 'Division of Neurology, Cincinnati Children's Research Foundation and University of Cincinnati College of Medicine, Cincinnati, OH, USA; \\ ${ }^{2}$ Department of Psychiatry, University of Cincinnati College of Medicine, Cincinnati, OH, USA; ${ }^{3}$ Sinclair Community College, Dayton, OH, USA
}

Many drugs are used or abused in social contexts without understanding the ramifications of their use. In this study, we examined the effects of a newly popular drug, 5-methoxy-diisopropyltryptamine (5-MEO-DIPT; 'foxy' or 'foxy-methoxy'). Two experiments were performed. In the first, 5-MEO-DIPT (0, 10 , or $20 \mathrm{mg} / \mathrm{kg}$ ) was administered to rats four times on a single day and animals were examined 3 days later. The animals that received 5-MEO-DIPT demonstrated hypothermia during the period of drug administration and delayed mild hyperthermic rebound for at least $48 \mathrm{~h}$. Corticosterone levels in plasma were elevated in a dose-dependent manner compared to saline-treated animals with minor changes in 5-HT turnover and no changes in monoamine levels. In experiment 2, rats were examined in behavioral tasks following either 0 or $20 \mathrm{mg} / \mathrm{kg}$ of 5-MEO-DIPT. The animals treated with 5-MEO-DIPT showed hypoactivity and an attenuated response to $(+)$-methamphetamine-induced stimulation $(\mathrm{I} \mathrm{mg} / \mathrm{kg})$. In a test of path integration (Cincinnati water maze), 5-MEO-DIPT-treated animals displayed deficits in performance compared to the saline-treated animals. No differences were noted in the ability of the animals to perform in the Morris water maze or on tests of novel object or place recognition. The data demonstrate that 5-MEO-DIPT alters the ability of an animal to perform certain cognitive tasks, while leaving others intact and disrupts the endocrine system. 5-MEO-DIPT may have the potential to induce untoward effects in humans.

Neuropsychopharmacology (2007) 32, 1404-1420. doi:I0.1038/sj.npp. I 301232; published online 18 October 2006

Keywords: Morris water maze; Cincinnati water maze; path integration; spatial learning; spontaneous locomotion

\section{INTRODUCTION}

The illicit use of 5-methoxy-diisopropyltryptamine (5-MEODIPT), commonly called 'foxy' or 'foxy methoxy', has gained popularity in the past several years as evidenced by increased seizures by the Drug Enforcement Administration (DEA) since 1999 (US Drug Enforcement Administration, 2003), as well as the number of mentions in the American Association of Poison Control Centers information database, TESS (Muller, 2004; Smolinske et al, 2004). 5-MEODIPT, like MDMA, is a 'club drug' popular at raves; because

*Correspondence: Dr MT Williams, Division of Neurology (MLC 7044), Cincinnati Children's Research Foundation, 3333 Burnet Avenue, Cincinnati, OH 45229-3039, USA, Tel: + I 5136368624 , Fax: + | 513636 39|2, E-mail: michael.williams@cchmc.org

4These authors contributed equally to this work.

Received 6 October 2005; revised 13 July 2006; accepted II August 2006

Online publication: I September 2006 at http://www.acnp.org/ citations/Npp090 1060506 I 3/default.pdf of its association with MDMA and abuse potential, it was classified as Schedule I as of September 2004 (Drug Enforcement Administration (DEA), 2004). The drug has been found to be in use throughout the United States, Canada, Japan, and Europe (Drug Enforcement Administration (DEA), 2004; EMCDDA, 2004; Kiyota, 2004; Meatherall and Sharma, 2003). Interestingly, even before the drug was scheduled in the United States, over 12000 tablets, 500 capsules, and $6.5 \mathrm{~kg}$ of 5 -MEO-DIPT were confiscated between 1999 and 2003 (Drug Enforcement Administration (DEA), 2004).

5-MEO-DIPT was first synthesized by Shulgin and Carter (1980) and was described as inducing auditory and visual hallucinations in humans lasting 3-6 h. Emergency room reports and recent case studies confirm the auditory and visual hallucinogenic properties of 5-MEO-DIPT and suggest that the drug can also produce tactile hallucinations, agitation, tachycardia, somatic disturbance, cataleptic states, unconsciousness, flashbacks, increased glucose levels, vomiting, rhabdomyolysis, and in at least one case, 
seizure activity or death (Alatrash et al, 2006; Ikeda et al, 2005; Kiyota, 2004; Meatherall and Sharma, 2003; Muller, 2004; Smolinske et al, 2004; Tanaka et al, 2006; Wilson et al, 2005). From case studies, users have reported administering various amounts of the drug (ie, $10-37.5 \mathrm{mg}$ ) via oral or rectal routes of administration (Ikeda et al, 2005; Kiyota, 2004). Although these doses were reported in several case studies, it is likely that they are not representative of all users, as the drug is used similarly to MDMA which is often taken in higher doses than those reported in these case studies on 5-MEO-DIPT.

The pharmacological mechanisms of action of 5-MEODIPT are not completely known. A comparison of the chemical structure of 5-MEO-DIPT with serotonin (5-HT) and MDMA (see Figure 1) shows that there are structural similarities between these compounds. Because of these similarities, 5-MEO-DIPT likely binds to serotonin receptors, although if it binds to the serotonin transporter or other receptor systems is unknown. In support of this hypothesis, 5-MEO-DIPT has been shown to generalize to 1-(2,5-dimethoxy-4-methyphenyl)-2-aminopropane (Glennon et al, 1983), another Schedule I hallucinogen that binds to subtypes of the 5- $\mathrm{HT}_{2}$ receptor (Eckler et al, 2003). The cataleptic states observed subsequent to 5-MEO-DIPT administration are also associated with $5-\mathrm{HT}_{2}$ agonists. A more recent report has confirmed that 5-MEO-DIPT binds to the $5-\mathrm{HT}_{2 \mathrm{~A}}, 5 \mathrm{HT}_{2 \mathrm{C}}$, and $5-\mathrm{HT}_{1 \mathrm{~A}}$ receptors (the only three receptors investigated in that study) (Fantegrossi et al, 2006). No other data exist describing potential mechanisms of action for 5-MEO-DIPT or the effects it might have on physiology and/or behavior in humans or animals. As 5-MEO-DIPT is sometimes sold as MDMA, its potential to produce MDMA-like reductions in monoamines needs to be elucidated.

Knowing the risks associated with the use of drugs with abuse potential is imperative (Johnston et al, 2004), and there are almost no data on 5-MEO-DIPT. Accordingly, we conducted two experiments to examine the lasting effects of the drug. The first experiment examined the effects on monoamines and neuroendocrine function, and the second examined functional changes following 5-MEO-DIPT administration.

\section{MATERIALS AND METHODS}

\section{Subjects}

Male Sprague-Dawley CD IGS rats, weighing 300-325 g ( $\sim$ P66-71) when purchased from Charles River Labora- tories, Raleigh, NC, were used as subjects in all experiments. Initially, the rats were housed in pairs in polycarbonate cages measuring $45.7 \times 23.8 \times 20.3 \mathrm{~cm}$ before drug administration. At least 1 week before being used, the rats were allowed to acclimate to the housing conditions (temperature, $19^{\circ} \mathrm{C}$ ) and $14 \mathrm{~h} \mathrm{light:} 10 \mathrm{~h}$ dark cycle (lights on at 0600 hours) in a vivarium fully accredited by the Association for the Assessment and Accreditation of Laboratory Animal Care. On the day before drug administration, animals were separated and maintained in this manner until required for physiological or behavioral testing. Separation of animals was done the day before drug administration, as animals are healthier when initially paired upon receipt and the $24 \mathrm{~h}$ time period allows the animals an acclimation period to separation; however, separation is required after drug administration to reduce aggression. Food and water were freely available throughout the experiments except during the period of drug administration. The Cincinnati Children's Research Foundation's Laboratory Animal Care and Use Committee approved all procedures.

\section{5-MEO-DIPT Administration}

5-Methoxy- $n, n$-diisopropyltryptamine-HCL (expressed as the freebase, Research Triangle Institute, NC; confirmed by $1 \mathrm{H}$ NMR spectroscopy) or isotonic saline vehicle (SAL) was administered on a single day. For Experiment 1, doses were 0,10 , or $20 \mathrm{mg} / \mathrm{kg}$ and in Experiment 2 they were 0 or $20 \mathrm{mg} / \mathrm{kg}$. 5-MEO-DIPT or SAL was administered four times at 2-h intervals on a single day (ie, the entire dosing period was $6 \mathrm{~h}$ from first to last dose). The multiple dose regimen is consistent with drug administration paradigms for other psychostimulants (Cappon et al, 1997; Cohen et al, 2005; Farfel and Seiden, 1995; O'Callaghan and Miller, 2002; O'Dell and Marshall, 2002). Injections were applied subcutaneously in the dorsum and the injection sites were varied to prevent irritation to the dermis, although some minor irritation was observed. During dosing, animals were maintained in $27.9 \times 16.5 \times 12.1 \mathrm{~cm}$ polycarbonate cages in a separate room from the colony at an average ambient temperature of $23.5^{\circ} \mathrm{C}$ for Experiment 1 and $23.7^{\circ} \mathrm{C}$ for Experiment 2. Animals were returned to the colony room $2 \mathrm{~h}$ after the last dose.

\section{Temperature Monitoring}

In order to monitor body temperature during drug administration, the animals were injected with implantable temperature transponders (IPTT-200; BMDS, Seaford, DE),

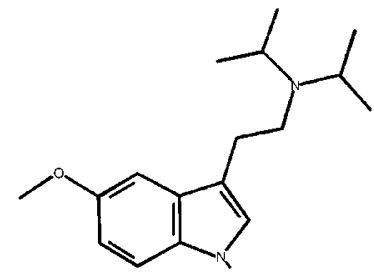

5-Meo-DIPT

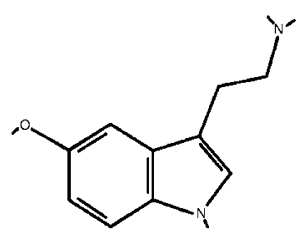

5-HT

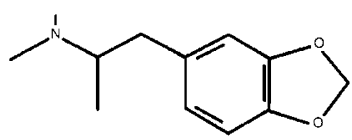

MDMA

Figure I Chemical structures of 5-methoxy-N,N-diisopropyltryptamine (5-MEO-DIPT), serotonin (5-HT), and 3,4-methylenedioxymethamphetamine (MDMA). PubChem Substance ID numbers 728723, 148566, and 180272, respectively. 
as described previously (Cohen et al, 2005; Skelton et al, 2004; Williams et al, 2002). Temperature transponders were implanted under isoflourane anesthesia 3 days before the experiment. This method reduces the need for intrusive handling of the animals, thereby avoiding additional stress effects (Balcombe et al, 2004) during the period of drug administration. Temperatures were monitored every $30 \mathrm{~min}$ beginning with the first injection and continuing until $2 \mathrm{~h}$ after the last injection. In Experiment 1, the animal's temperature was also obtained at $12 \mathrm{~h}$ following the first dose. Additional temperatures at the 24,48 , and $72 \mathrm{~h}$ time points were also obtained in both experiments.

In order to prevent death from anticipated hyperthermia induced by drug administration, any rat that had a temperature in excess of $40^{\circ} \mathrm{C}$ was placed in a shallow cooling bath of water until the temperature fell below $40^{\circ} \mathrm{C}$. During the cooling procedure, the temperature of the animal was checked every $10 \mathrm{~min}$ to ensure that overcooling did not occur. Once the animal's temperature fell below $40^{\circ} \mathrm{C}$, it was removed from the water and returned to its test cage. This procedure, however, was only required for one animal in Experiment 1 that received $20 \mathrm{mg} / \mathrm{kg}$ of 5-MEO-DIPT and this animal was only cooled once for $10 \mathrm{~min}$. No other animals in experiment 1 or 2 were cooled.

\section{Body Weights}

Animals were weighed immediately before drug administration and at the end of temperature collection (ie, $8 \mathrm{~h}$ after the first dose). For Experiment 1, animals were also weighed at 24 and $48 \mathrm{~h}$ after the last drug administration, as well as $4 \mathrm{~h}$ before killing (ie, $68 \mathrm{~h}$ after the last dose). In Experiment 2 , animals were weighed weekly.

\section{Experiment 1}

In Experiment 1, we examined the potential of 5-MEO-DIPT to alter monoamine and neuroendocrine parameters. There were three treatments, 0,10 , and $20 \mathrm{mg} / \mathrm{kg} 5$-MEO-DIPT with $n=9,9$, and 11 , respectively. At $72 \mathrm{~h}$ after the last dose, animals were taken individually to an adjacent suite, decapitated, and trunk blood was collected in polyethylene tubes $(12 \times 75 \mathrm{~mm})$ containing $2 \%$ EDTA $(0.05 \mathrm{ml} /$ tube) . Following collection of trunk blood for plasma, glucose values were obtained from trunk blood without EDTA using a commercially available glucometer (Precision Xtra, MediSense).

The brain was rapidly removed, placed over ice, and the following regions were dissected: prefrontal cortex, neostriatum, hypothalamus, and hippocampus, with the aid of a brain block (Zivic-Miller, Pittsburgh, PA). The brain was first sliced coronally at the optic chiasm and the neostriatum was dissected freehand from a block of tissue that was $2 \mathrm{~mm}$ immediately rostral to this first coronal cut. The prefrontal cortex was obtained from a $2 \mathrm{~mm}$ section beginning at the anterior pole of the frontal association cortex after removal of the olfactory bulbs and tubercles. The hypothalamus was dissected by making lateral cuts at the hypothalamic sulci, a coronal cut at the posterior portion of the mammillary body, and a horizontal cut at the roof of the third ventricle. The remaining forebrain was sliced sagitally and the hippocampus removed from the cerebral hemispheres. All tissues were frozen on dry ice immediately upon dissection and then stored at $-80^{\circ} \mathrm{C}$ until assayed for monoamines.

The adrenal glands, thymus, and spleen were removed, freed of fatty tissue, and weighed. The tissue data were expressed as a percentage of tissue (mg) weight $v s$ body weight $(\mathrm{g})$. Tissues were collected to determine if changes occurred at these sites following drug administration, as these organs are known to be affected by hormones of the hypothalamic-pituitary-adrenal (HPA) axis, particularly during increased activation of this pathway (Akana et al, 1983; Bakker et al, 1997; Kioukia-Fougia et al, 2002; Selye, 1936).

\section{Corticosterone Assessment}

The trunk blood was centrifuged (1399 RCF) for $25 \mathrm{~min}$ at $4{ }^{\circ} \mathrm{C}$, plasma collected, and stored at $-80^{\circ} \mathrm{C}$ until assayed. Before the determination of corticosterone (CORT), plasma was diluted 3:1 in assay buffer and assayed in duplicate using commercially available EIAs for CORT (IDS, Fountain Hills, AZ). The EIA has little crossreactivity with other hormones or precursors.

\section{Monoamine Assessment}

High-pressure liquid chromatography (HPLC) analysis of monoamine levels was performed as described previously (Koprich et al, 2003). Briefly, samples were homogenized in an antioxidant solution, centrifuged for $20 \mathrm{~min}$ at $14000 \mathrm{~g}$ and the supernatant was collected for HPLC. A Microsorb MV C-18 column $(5 \mu \mathrm{m}, 4.6 \times 250 \mathrm{~mm}$, Varian, Walnut Creek, CA) attached to a 12-channel coulometric array detector (CoulArray 5200, ESA, Chelmsford, MA) and Waters 2695 Solvent Delivery System (Waters, Milford, MA) was used to determine concentrations of norepinephrine (NE), dopamine (DA), 3,4-dihydroxyphenylacetic acid (DOPAC), homovanillic acid (HVA), 5-hydroxyindolacetic acid (5-HIAA), and serotonin (5-HT). A flow rate of $1 \mathrm{ml} / \mathrm{min}$ with detection potentials of $50,175,350,400$, and $525 \mathrm{mV}$ were used. The mobile phase consisted of a $10 \%$ methanol solution containing $0.1 \mathrm{M}$ citric acid, $0.075 \mathrm{M}$ $\mathrm{Na}_{2} \mathrm{HPO}_{4}, 0.8 \mathrm{mM}$ heptanesulfonic acid, and $0.097 \mathrm{mM}$ EDTA at a final $\mathrm{pH}$ of 4.1. The concentration of monoamines in the tissue samples was quantified against a six-point standard curve. The amount of protein in each sample was determined (Pierce BCA Protein Reagent Kit, Rockford, IL) and monoamines were expressed as ng/mg protein.

\section{Experiment 2}

In experiment 2, we examined the potential of 5-MEO-DIPT to alter behavior using either 0 or $20 \mathrm{mg} / \mathrm{kg} \quad(n=12 /$ treatment). Animals were tested in the following procedures: spontaneous locomotor activity, marble burying, straight channel swimming, Cincinnati water maze (CWM), Morris water maze (MWM), novel object and place recognition, locomotor activity following a methamphetamine challenge, and a delayed probe trial in the MWM. All tests were performed during the light phase of the light/dark cycle. This order of testing closely follows one that we have 
used to assess the impact of a single day exposure to other psychostimulants in adult animals (Cohen et al, 2005; Skelton et al, 2004; Williams et al, 2002). We have previously shown that the order of the CWM and MWM does not significantly affect the outcome with these compounds (Williams et al, 2002). Following the delayed probe trial, animals were decapitated and plasma and brain tissue collected.

\section{Spontaneous Locomotion}

On the third day after drug administration, animals began behavioral assessment in the spontaneous locomotor activity test. The apparatus, a Digiscan rxyz-16 activity monitor (Accuscan Electronics, Columbus, $\mathrm{OH}$ ), was $41 \times 41 \mathrm{~cm}$ and contained 16 photodetector-LED pairs along each side spaced $2.5 \mathrm{~cm}$ apart and positioned $2.2 \mathrm{~cm}$ above the floor of the test chamber. To begin the test, an animal was placed in the apparatus and following $1 \mathrm{~h}$ of exploration, the task was ended. The dependent variables were horizontal activity, which is the sum of all photobeam interruptions occurring in the horizontal plane, and stereotypy, which is the sum of repetitive sequential photobeam breaks at the same position. The activity chambers were thoroughly cleaned between animals with $70 \%$ ethanol.

\section{Marble Burying}

Immediately following the spontaneous locomotor task, animals were brought to an adjacent suite and tested in the marble burying test as adapted from a previous procedure (Njung'e and Handley, 1991). Specifically, 18 blue marbles $1.44 \mathrm{~cm}$ in diameter (blue was a color that produced greater burying compared to clear marbles in a preliminary study) were evenly placed (approximately $3.5 \mathrm{~cm}$ from the sides and spaced $7 \mathrm{~cm}$ apart in all directions) in six rows of three (a template was used to position the marbles within the cage) in a normal rat cage measuring $45.7 \times 23.8 \times 20.3 \mathrm{~cm}$. Fresh wood chip bedding $(5 \mathrm{~cm}$ deep) was placed in each cage and a filter top was used to cover the cage. Animals were given $30 \mathrm{~min}$ of exposure to the marbles. After $30 \mathrm{~min}$, the number of marbles at least $2 / 3$ buried and the total number of visible marbles were counted. New cages and bedding were used for each animal and the marbles were cleaned with $70 \%$ ethanol between animals.

\section{Straight Channel}

In order to ensure that the drug paradigm did not affect motor ability and/or motivation to escape from water, animals were examined for swimming ability in a $244 \mathrm{~cm}$ water-filled straight channel as described previously (Williams et al, 2003b). At 6 days after drug administration, each rat received four timed consecutive trials (maximum time $=2 \mathrm{~min} /$ trial) to swim the length of the channel to locate an escape ladder positioned at the opposite end. Animals were released in the water facing the wall opposite the escape ladder. The water temperature was $22 \pm 1^{\circ} \mathrm{C}$. An added benefit of this procedure is that the animals were exposed to swimming before learning to escape in the water mazes.

\section{Cincinnati Water Maze}

Beginning 1 week after drug administration, animals were assessed for their ability to learn the CWM. The CWM was originally described by Vorhees (1987). Briefly, the maze was composed of a series of nine acrylic T's that form a central channel. The width of the arms of the Ts and the channel is $15.2 \mathrm{~cm}$ and the height of the walls is $50.8 \mathrm{~cm}$. Water was at room temperature $\left(21 \pm 1^{\circ} \mathrm{C}\right)$ and filled to a depth of $25 \mathrm{~cm}$. All testing was carried out under a single $25 \mathrm{~W}$ red light bulb to reduce the availability of visible cues. The animals were started facing the wall from the ' $\mathrm{B}$ ' position (as defined by Vorhees, 1987) and allowed a maximum of $5 \mathrm{~min}$ per trial to find the escape ramp. There was a 5 min intertrial interval (ITI) if an animal failed to locate the goal within the time limit, otherwise it was retested immediately. If an animal failed to locate the escape, it was removed from the water and replaced in its home cage. Animals were given two daily trials for 7 days. The dependent measures for the CWM were latency to reach the escape ramp, number of errors committed in each trial (errors of commission), and the number of returns to the start position. An error was defined as a whole body entry in a dead-end arm of a T. Perseverations within a given $\mathrm{T}$ were counted as individual errors.

\section{Morris Water Maze}

Testing in the MWM began 2 weeks after drug administration, and was conducted in several phases. The MWM apparatus was $210 \mathrm{~cm}$ in diameter and filled with room temperature water $\left(22 \pm 1^{\circ} \mathrm{C}\right)$. One of two goal platform sizes, either $10 \times 10 \mathrm{~cm}$ or $5 \times 5 \mathrm{~cm}$, was used depending upon the phase of testing (see below). A camera attached to a computer and monitor automatically tracked the performance of each rat using a video tracking system (Smart software, SDI, San Diego, CA). The maze was arbitrarily divided at four cardinal points designated N, S, E, W, where $\mathrm{N}$ was defined as the position farthest from the experimenter. The platform was first located in the SW quadrant for the acquisition phase, in the NE quadrant for the reversal phase, and in the NW quadrant for the shift phase. The start positions were defined previously (Williams et al, 2003a) and included only positions that did not release the animal in the goal quadrant. For example, when the platform was located in the SW quadrant, the starting points were $\mathrm{N}, \mathrm{E}, \mathrm{NW}, \mathrm{SE}$, and when the platform was located in the NE quadrant, the starting points were $S, W$, $\mathrm{SE}$, and NW, and for the NW quadrant, starting points were $\mathrm{S}, \mathrm{E}, \mathrm{SW}$, and NE. The start positions were quasirandomized with the stipulation that no position could be used more than once a day.

There were seven test phases: three learning phases, acquisition (place learning to a $10 \times 10$ platform), reversal (place learning to a $10 \times 10 \mathrm{~cm}$ platform in the opposite quadrant), and shifted (place learning to the quadrant adjacent to the reversal quadrant with a $5 \times 5 \mathrm{~cm}$ platform), three memory phases (one probe trial after each of the learning phases), and a final memory trial 16 days after the end of the shift phase. For all of the learning phases, each rat received four trials per day for 5 days with a two-min trial limit and an ITI of $15 \mathrm{~s}$ (spent on the platform). If a rat 
failed to locate the platform, it was removed from the water and placed on the platform. On the day following each of the learning phases, a $30 \mathrm{~s}$ probe trial was administered. During the probe trial, the platform was removed and the animal was started $180^{\circ}$ from the platform and allowed $30 \mathrm{~s}$ to search the tank. Following the acquisition learning and memory phases, the platform was moved to the opposite quadrant, NE, and animals began testing in the reversal phase beginning 3 weeks after drug administration. The day following the reversal phase, another $30 \mathrm{~s}$ probe trial was administered. For the fifth phase, the platform was moved to the NW quadrant (shift phase; week 4 after dosing). Two memory phases were assessed following this phase, the first was 1 day after learning and the other was 16 days after learning. The dependent measures for the learning trials were latency and path length. For memory (probe) trials, the dependent measures were latency to and average distance from the platform site and the number of platform site crossings. Average distance parameters were recorded every $0.2 \mathrm{~s}$.

\section{Novel Object and Novel Place Recognition}

Novel object recognition testing began 5 weeks after dosing. The apparatus for this test were circular polyethylene arenas measuring $91 \mathrm{~cm}$ in diameter with $51 \mathrm{~cm}$ high walls. Before recognition testing, animals were habituated by placing them in the arena for $10 \mathrm{~min}$ per day for 4 days. Novel object recognition testing took place on the fifth day and was divided in two phases, familiarization and retention. The familiarization phase entailed placing two identical objects $25 \mathrm{~cm}$ from the sides of the arena and $41 \mathrm{~cm}$ apart, on center, and then each rat, in turn, was placed in the arena between the two objects and given a maximum of $10 \mathrm{~min}$ to accumulate $30 \mathrm{~s}$ of object exploration as defined previously (Clark et al, 2000). Object exploration was recorded when the animal was in close proximity $(\sim 1 \mathrm{~cm})$ and oriented to the object and if the animal sniffed or pawed the object (Clark et al, 2000). The retention phase began $1 \mathrm{~h}$ after familiarization and an identical object to those used in the familiarization phase and a novel object were placed in the test arena. Animals were again allowed $10 \mathrm{~min}$ to complete $30 \mathrm{~s}$ of object exploration. The novel place recognition test was performed the day after the novel object recognition test. For the novel place recognition test, new, identical familiarization objects were placed in the arena and animals were tested as described for novel object recognition. During the retention phase, two identical objects as used in the familiarization phase were placed in the apparatus, but one of the objects was displaced $90^{\circ}$ from the original position. A video camera was placed over the testing arena, and behavior was scored manually. The dependent measure was the amount of time spent with either the novel object or the object in the new location and amount of time to accumulate the $30 \mathrm{~s}$ of object exploration. The test arena was cleaned between animals with $70 \%$ ethanol.

\section{Locomotor Assessment with Methamphetamine Challenge}

At 2 days after the completion of the novel place task, animals were placed in the locomotor activity chambers described above. The animals were allowed $30 \mathrm{~min}$ of exploration time in the chamber and then briefly removed from the chamber, and (+)-methamphetamine $(1 \mathrm{mg} / \mathrm{kg}$ subcutaneously in the dorsum, obtained from NIDA) was administered. Animals were then replaced in the activity chamber and monitored for $2 \mathrm{~h}$ and both horizontal activity and stereotypy were measured. After the completion of the task, animals were returned to their home cage and the chambers were cleaned with $70 \%$ ethanol.

\section{Delayed Probe Trial in the MWM}

At 1 week after the locomotor test with methamphetamine challenge, animals were re-tested in the MWM for their memory of the location of the $5 \times 5 \mathrm{~cm}$ platform. As this was a memory trial, the platform was removed from the pool and the animals had $30 \mathrm{~s}$ of exploration time in the task.

\section{Tissue Collection}

Following the completion of this task, animals were returned to the home cage for $10 \mathrm{~min}$ and then brought to an isolated suite, decapitated and trunk blood, brain regions (PFC, neostriatum, and hippocampus), thymus, adrenals, and spleen were collected as described above.

\section{Statistics}

For Experiment 1, mixed factor analyses of variance (ANOVA) were used to determine significance for temperature, percent change in body weight, and neurotransmitters and metabolites using PROC GLM (SAS Institute, Cary, NC). The between factor variable was Treatment $(0,10$, or $20 \mathrm{mg} / \mathrm{kg}$ 5-MEO-DIPT) and the within subject factor was Time for temperature measurements and body weights and brain regions for neurotransmitters and metabolites. Adrenal, thymus, and spleen weights, corticosterone and glucose concentration data were all subjected to a one-way ANOVA.

In Experiment 2, mixed factor analyses were performed on temperature, percent change in body weight, and neurotransmitters as described above. Mixed factor ANOVAs were also performed on the behavioral data. In these models, treatment was a between factor, whereas within factors varied for each task. The within subject factors for each task were: spontaneous locomotor activity and locomotor activity with challenge (5 min intervals), straight channel swimming (trials), CWM latency, errors, returns to start (day), and MWM for learning phases (day). When an analysis contained a within factor, the Huynh-Feldt correction was used when the symmetry of the variancecovariance matrices were significantly nonspherical. Simple-effect ANOVAs were used to further analyze significant interactions and step-down F-tests were used to determine group differences in Experiment 1 (Kirk, 1995). Student's $t$-tests for independent samples (two-tailed) were performed for all other a posteriori comparisons using PROC T TEST in SAS. Satterthwaite corrections were used when the variances were unequal. In rare cases where a biochemical result was $>5$ standard deviations from the mean, it was removed from further analysis. Data are presented as 
means \pm SEM, unless otherwise noted. Significance was set at $p \leqslant 0.05$ and trends were considered at $p \leqslant 0.1$.

\section{RESULTS}

\section{General Description}

One animal receiving $20 \mathrm{mg} / \mathrm{kg}$ of 5 -MEO-DIPT died $1.5 \mathrm{~h}$ after the first drug administration, therefore $n=10$ for the $20 \mathrm{mg} / \mathrm{kg}$ treatment group. No other animals died during or after drug administration. During the course of 5-MEODIPT administration, some of the animals showed signs of seizure activity as indicated by myoclonus of the hind legs and jaw. All of the animals receiving $20 \mathrm{mg} / \mathrm{kg}$ of $5-\mathrm{MEO}-$ DIPT showed some myoclonus during the period of drug administration, whereas only five of nine animals that received $10 \mathrm{mg} / \mathrm{kg}$ of 5 -MEO-DIPT displayed this behavior. Some of the animals also had a splayed body posture shortly after drug administration. All these symptoms resolved by the end of the temperature collection period (ie, within $2 \mathrm{~h}$ of the last dose).

\section{Temperatures}

In Experiment 1, there were no differences in the initial body temperatures among groups. There were significant Treatment, $\mathrm{F}(2,24)=11.4, p<0.0003$, and Time, $\mathrm{F}(20$, $480)=84.22, p<0.001$, effects as well as the interaction of Treatment $\times$ Time, $F(40,480)=14.2, p<0.0001$ on postdrug body temperature. Examination of Figure 2a demonstrates that animals that received 5-MEO-DIPT, regardless of dose, began showing hypothermia relative to saline animals beginning approximately $120 \mathrm{~min}$ after the first dose $(p<0.1)$ and were significantly decreased compared to saline-treated animals beginning at $180 \mathrm{~min}(p<0.001)$. This hypothermic response continued until $480 \mathrm{~min}$ for both 5 -MEO-DIPT treatment groups $(p<0.0001)$. At $15 \mathrm{~h}$, only the animals that received $20 \mathrm{mg} / \mathrm{kg}$ of $5-\mathrm{MEO}-\mathrm{DIPT}$ showed the hypothermic response (Figure $2 \mathrm{~b}$ ). At both the 24 and $48 \mathrm{~h}$ time points, the 5-MEO-DIPT-treated animals had higher body temperatures relative to the saline-treated animals $(p<0.0001)$. With the exception of a slight difference at $480 \mathrm{~min}(p<0.08)$ and a significant difference at the $15 \mathrm{~h}$ time point $(p<0.01)$, the animals treated with
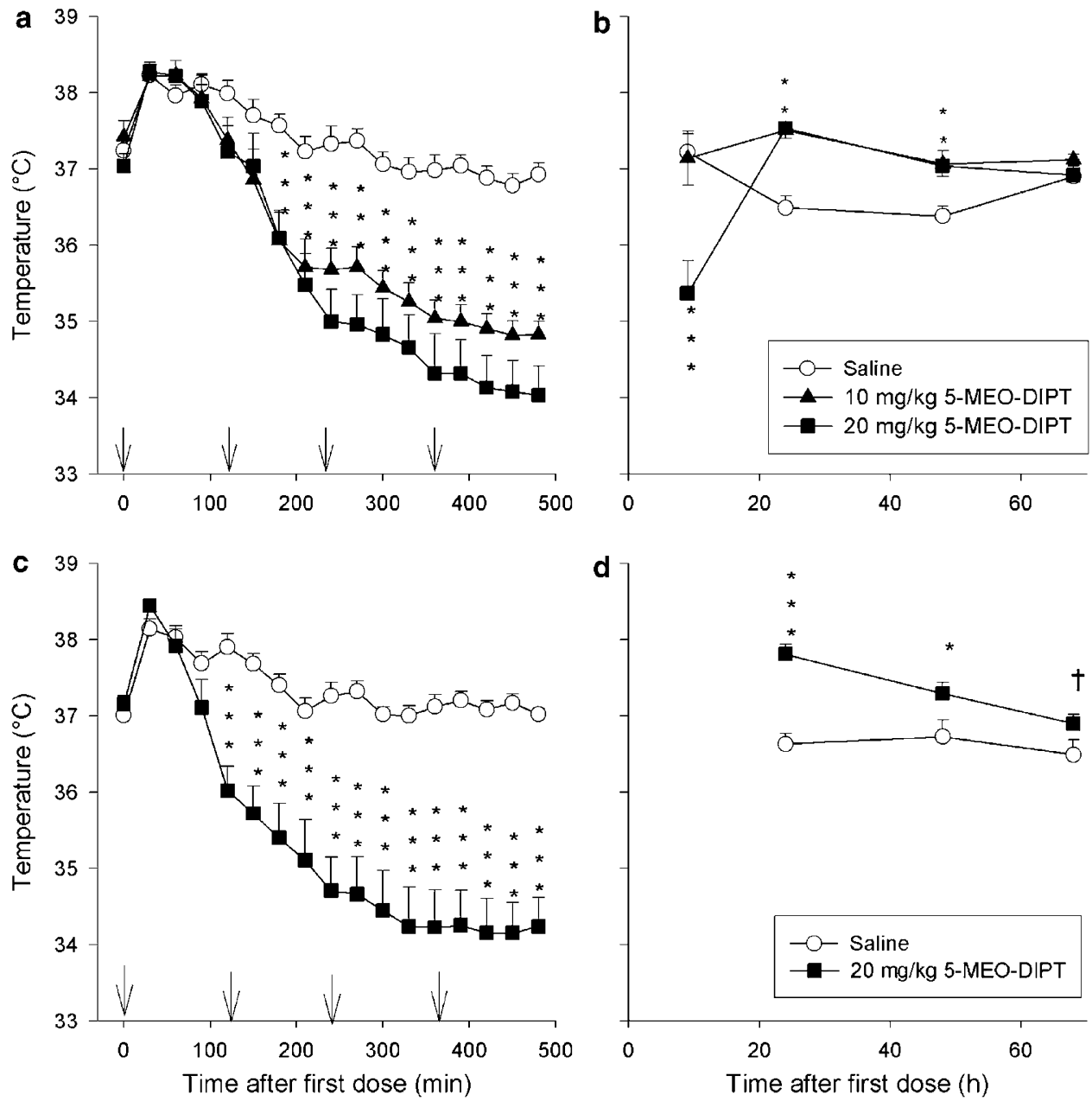

Figure 2 The body temperatures of animals in Experiment I ( $a, b)$ and Experiment 2 (c, d). No differences in the initial temperatures were observed; however, 5-MEO-DIPT produced significant decreases in body temperature during the course of drug administration. Following drug administration, at $24 \mathrm{~h}$ and $48 \mathrm{~h}$ after the last dose, animals treated with 5-MEO-DIPT had increased body temperatures. The arrows represent the points where 5-MEO-DIPT was administered. $* 0 \leqslant 0.05, * * 0.01, * * * * \leqslant 0.001,{ }^{\dagger} p \leqslant 0.1$ vs saline. 
$10 \mathrm{mg} / \mathrm{kg}$ did not differ from the animals treated with $20 \mathrm{mg} / \mathrm{kg}$ of 5-MEO-DIPT.

In experiment 2, animals either received $20 \mathrm{mg} / \mathrm{kg}$ of 5-MEO-DIPT or saline and a similar pattern of temperatures was observed as shown in Figure $2 \mathrm{c}$ and d. Again, the starting temperatures were similar between the treatments. There were significant main effects of Treatment, $\mathrm{F}(1,19)=20.59$, $p<0.0002$, and Time, $\mathrm{F}(19,361)=40.27, p<0.0001$ and also the Treatment $\times$ Time interaction, $\mathrm{F}(19,361)=30.38$, $p<0.0001$. At $30 \mathrm{~min}$, the 5-MEO-DIPT animals had slightly higher temperatures $(p<0.05)$; however, similar temperatures were observed until $120 \mathrm{~min}$ between treatments. Beginning at $120 \mathrm{~min}$, the 5-MEO-DIPT-treated animals again showed a decrease in body temperature compared to the saline-treated animals that lasted until at least $480 \mathrm{~min}$ after the first dose $(p<0.0001)$. However, by $24 \mathrm{~h}$ and continuing until $48 \mathrm{~h}, 5-\mathrm{MEO}-\mathrm{DIPT}$ animals had higher body temperatures $(p<0.0001$ and 0.05 , respectively). A slight increase was still observed at $68 \mathrm{~h}(p<0.09)$.

\section{Body Weights}

For both Experiment 1 and 2, the body weights of the animals were first analyzed to determine whether there were any differences at the beginning of treatment. Subsequent analyses examined the percent change in body weight relative to the initial weight (Figure $3 a$ and $b$ ). In Experiment 1, there were no differences in the initial weights; however, there were significant main effects of Treatment, $\mathrm{F}(2,25)=14.1, p<0.0001$, and Time, $\mathrm{F}(4,100)=$ $45.42, p<0.0001$, and the interaction of Treatment $\times$ Time, $\mathrm{F}(8,100)=7.38, p<0.0001$ (Figure $3 \mathrm{a}$ ) for the percent weight change. Further analyses of the interaction showed that the animals treated with $20 \mathrm{mg} / \mathrm{kg}$ of 5-MEO-DIPT had a decrease in body weight at all time points $(2,24,48$, and $68 \mathrm{~h}$ after the last dose) compared to the saline-treated animals $(p<0.006)$. The $20 \mathrm{mg} / \mathrm{kg}$-treated animals showed a trend toward less weight gain over all time points compared to the $10 \mathrm{mg} / \mathrm{kg}$-treated animals $(p<0.06)$. With the exception of the $24 \mathrm{~h}$ time point, the $10 \mathrm{mg} / \mathrm{kg}$-treated animals had lower body weights than the saline-treated animals $(p<0.007)$.

For Experiment 2 body weights, there was a significant increase in body weight over Time, $\mathrm{F}(6,132)=101.34$, $p<0.0001$, regardless of Treatment. Additional comparisons were performed at the $2 \mathrm{~h}$ and 1-week time points. A decrease in body weight gain for the 5-MEO-DIPT-treated animals compared to saline-treated animals was observed at the $2 \mathrm{~h}$ time point, $t(22)=8.09, p<0.0001$ and this decrease in body weight gain continued through the first week, $t(22)=2.59, p<0.02$ (Figure 3b). No differences in body weight were noted after the first week although a trend is evident in Figure $3 b$ at 2 weeks.

\section{Experiment 1}

Neurotransmitters. For each neurotransmitter and metabolite (Table 1), a mixed factor ANOVA was employed and for all neurochemicals examined, there was a significant effect of Region $(p<0.0001)$. For NE, there was a trend for Treatment, $p<0.06$ and the Treatment $\times$ Region interaction, $p<0.09$.
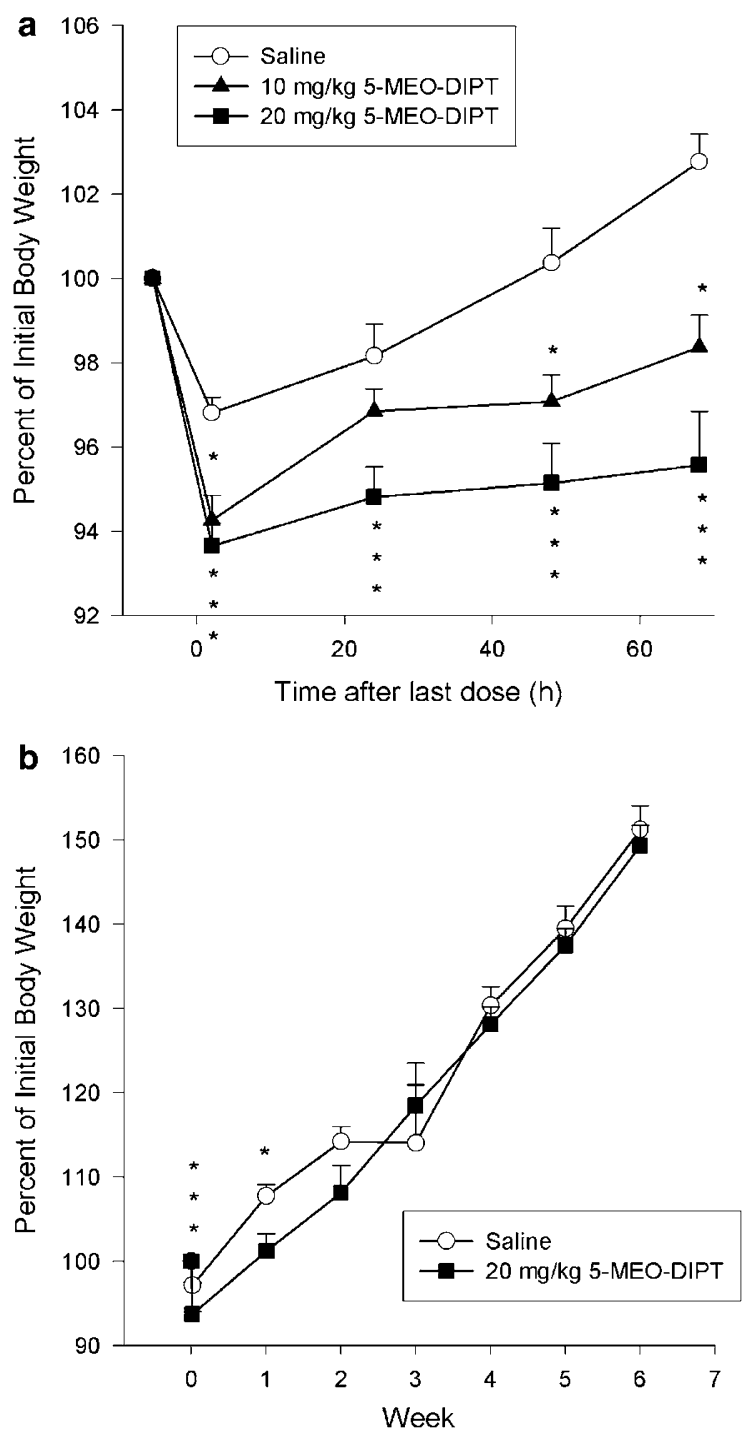

Figure 3 The percent change in body weights from the preadministration weight of animals from Experiment I (a) and Experiment 2 (b) are shown. In Experiment I, there was a decrease in body weights throughout the $72 \mathrm{~h}$ period in the 5-MEO-DIPT-treated animals. Note, for Experiment 2 , the body weights begin with the weight taken $2 \mathrm{~h}$ after the last dose, rather than before treatment as in experiment I; as can be seen, 5-MEODIPT-treated animals had reduced body weights relative to the salinetreated animals. $* p \leqslant 0.05$, **** $p \leqslant 0.00$ I vs saline.

For DA, DOPAC, HVA, the ratio of DOPAC/DA, the ratio of HVA/DA, 5-HT or 5-HIAA, there was neither an effect of Treatment nor an interaction of Treatment $\times$ Region. However, the ratio of 5-HIAA/5-HT did reveal a significant interaction of Treatment $\times$ Region, $\mathrm{F}(6,75)=2.93, p<0.02$. Analyses of the interaction showed that there were significant Treatment differences in the striatum and hypothalamus $(p<0.05)$ and a trend in the prefrontal cortex $(p=0.1)$. Specifically, the animals treated with either 20 or $10 \mathrm{mg} / \mathrm{kg}$ of 5 -MEO-DIPT had higher ratios of 5 HIAA/5-HT in the neostriatum and hypothalamus relative to the saline-treated animals. The $20 \mathrm{mg} / \mathrm{kg}$-treated animals also had lower 5-HIAA/5-HT ratios in the prefrontal cortex compared to the saline-treated animals. No differences were noted between the $20 \mathrm{mg} / \mathrm{kg}$ - and $10 \mathrm{mg} / \mathrm{kg}$-treated animals. 
Table I Regional Levels of Neurotransmitters (ng/mg Protein) in Animals from Experiment I

\begin{tabular}{|c|c|c|c|c|c|c|c|c|c|c|c|}
\hline Region & $\mathrm{mg} / \mathrm{kg}$ & $N$ & NE & DA & DOPAC & HVA & DOPAC/DA & HVA/DA & $5-\mathrm{HT}$ & 5-HIAA & 5-HIAA/5-HT \\
\hline \multirow[t]{3}{*}{ Prefrontal cortex } & 0 & 9 & $3.74 \pm 0.27$ & $0.29 \pm 0.06$ & $0.22 \pm 0.02$ & $0.15 \pm 0.03$ & $1.10 \pm 0.30$ & $0.87 \pm 0.32$ & $5.91 \pm 0.37$ & $10.52 \pm 0.62$ & $1.80 \pm 0.10$ \\
\hline & 10 & 9 & $4.07 \pm 0.19$ & $0.40 \pm 0.07$ & $0.24 \pm 0.02$ & $0.22 \pm 0.02$ & $0.81 \pm 0.19$ & $0.75 \pm 0.20$ & $6.88 \pm 0.45$ & $|1.39 \pm 0.9|$ & $1.67 \pm 0.10$ \\
\hline & 20 & 10 & $3.94 \pm 0.16$ & $0.42 \pm 0.13$ & $0.24 \pm 0.06$ & $0.20 \pm 0.05$ & $0.69 \pm 0.08$ & $0.63 \pm 0.13$ & $6.58 \pm 0.34$ & $9.65 \pm 0.49$ & $1.49 \pm 0.09 *$ \\
\hline \multirow[t]{2}{*}{ Neostriatum } & 0 & 9 & $1.70 \pm 0.21$ & $128.01 \pm 13.36$ & $25.00 \pm 2.62$ & $9.08 \pm 0.85$ & $0.20 \pm 0.01$ & $0.07 \pm 0.004$ & $8.40 \pm 0.50$ & $14.73 \pm 0.78$ & $1.77 \pm 0.05$ \\
\hline & 20 & 10 & $1.63 \pm 0.32$ & $149.82 \pm|4.2|$ & $29.81 \pm 2.51$ & $10.65 \pm 0.67$ & $0.21 \pm 0.01$ & $0.07 \pm 0.004$ & $7.62 \pm 0.65$ & $16.56 \pm 1.73$ & $2.15 \pm 0.06 *$ \\
\hline \multirow[t]{3}{*}{ Hypothalamus } & 0 & 9 & $23.40 \pm 0.93$ & $6.71 \pm 0.49$ & $0.82 \pm 0.07$ & $0.20 \pm 0.02$ & $0.12 \pm 0.006$ & $0.03 \pm 0.002$ & $11.20 \pm 0.35$ & $11.24 \pm 0.36$ & $\quad 1.01 \pm 0.04$ \\
\hline & 10 & 9 & $20.96 \pm 1.48$ & $6.68 \pm 0.68$ & $0.88 \pm 0.08$ & $0.27 \pm 0.03$ & $0.13 \pm 0.01$ & $0.04 \pm 0.003$ & $11.26 \pm 0.60$ & $12.64 \pm 0.40$ & $1.14 \pm 0.05^{*}$ \\
\hline & 20 & 10 & $|9.82 \pm 0.7|$ & $5.74 \pm 0.33$ & $0.76 \pm 0.05$ & $0.20 \pm 0.01$ & $0.13 \pm 0.003$ & $0.03 \pm 0.002$ & $10.92 \pm 0.27$ & $12.40 \pm 0.26$ & $1.14 \pm 0.04 *$ \\
\hline
\end{tabular}

* $p<0.05$.

Peripheral measurements. Corticosterone and glucose were examined in the plasma and adrenal, thymus, and spleen were weighed. For corticosterone, there was a significant effect of Treatment, $F(2,23)=3.79, p<0.05$. The animals that received $20 \mathrm{mg} / \mathrm{kg}$ had increased levels of CORT, even 3 days after the dosing period, compared to saline-treated animals (Figure 4a). No differences were noted between the $10 \mathrm{mg} / \mathrm{kg}$-treated animals and either the saline- or $20 \mathrm{mg} / \mathrm{kg}$ treated animals. No differences in glucose were found (not shown).

The weights of the thymus, spleen, and adrenals were expressed as a percentage of body weight. For the adrenal gland, there was a significant effect of Treatment, $\mathrm{F}(2,25)=9.67, p<0.001$ (Figure $4 \mathrm{~b}$ ). Regardless of the dose of 5-MEO-DIPT, animals treated with 5-MEO-DIPT had adrenal hypertrophy compared to the saline-treated animals. It should be noted that the hypertrophy in the 5-MEODIPT treated animals was evident regardless of whether the adrenal weight was expressed as a percentage of body weight or as a raw weight $(\mathrm{F}(2,25=6.70, p<0.005$, not shown). No differences were noted for either the thymus or the spleen among Treatments (Figure 4c and $\mathrm{d}$ ) when expressed as a percentage of body weight; however, there was a significant reduction in unadjusted thymus weights for the $20 \mathrm{mg} / \mathrm{kg}$-treated animals compared to saline-treated animals (not shown).

\section{Experiment 2}

Spontaneous locomotor activity and marble burying. Animals were initially assessed for spontaneous locomotor immediately followed by marble burying 3 days after drug administration. The records of six animals in locomotor activity were lost due to a computer malfunction, therefore $n=8$ saline-treated animals and 10, 5-MEO-DIPT-treated animals for this task. For horizontal activity, there was a significant effect of Treatment, $\mathrm{F}(1,16)=5.22, p<0.04$, and Interval, $\mathrm{F}(11,176)=33.34, p<0.0001$, and the interaction of
Treatment $\times$ Interval, $\mathrm{F}(11,176)=4.48, p<0.0002$. As displayed in Figure $5 \mathrm{a}$, horizontal activity of the animals declined over the $1 \mathrm{~h}$ testing period. Animals treated with 5-MEO-DIPT showed hypoactivity compared to the salinetreated animals and this effect was the result of significantly less locomotion during the first three intervals $(p<0.05)$ and a trend for reduced levels during the fourth interval (ie, $20 \mathrm{~min}, p=0.09$ ).

For the stereotypy scores, there was a significant effect of Interval, $\mathrm{F}(11,176)=28.53, p<0.0001$, and the interaction of Treatment $\times$ Interval, $\mathrm{F}(11,176)=2.38, p<0.009$, Figure $5 \mathrm{~b}$. As with horizontal activity, stereotypy scores decreased overtime. Furthermore, the 5-MEO-DIPT-treated animals showed a reduction in the number of stereotypy scores during the first $15 \mathrm{~min}$ of testing. By the end of testing, at interval 11 , the number of stereotypy scores was increased in the 5-MEO-DIPT-treated animals compared to the salinetreated animals (Figure 5b), although it should be noted that no differences in horizontal activity were observed at this time. No treatment-related differences were noted for the number of rears or time spent in the periphery (ie, $3 \mathrm{~cm}$ from the wall of the test arena), although these behaviors decreased over time $(p \leqslant 0.001)$.

For marble burying, no effect was observed following 5-MEO-DIPT administrations on the number of marbles buried. The saline-treated animals buried on average $11.3 \pm 1.92$ marbles out of 18 , whereas the animals treated with 5-MEO-DIPT buried on average $8.67 \pm 2.19$ marbles out of 18 .

Straight channel. At 6 days after drug administration, animals were tested in the straight channel. All animals were able to locate the escape platform in the straight channel and the latency to locate the escape ladder decreased over trials regardless of Treatment, $\mathrm{F}(3,66)=18.3, p<0.0001$. No effect of Treatment or the interaction of Treatment $\times$ Trials was significant in these animals (not shown). 

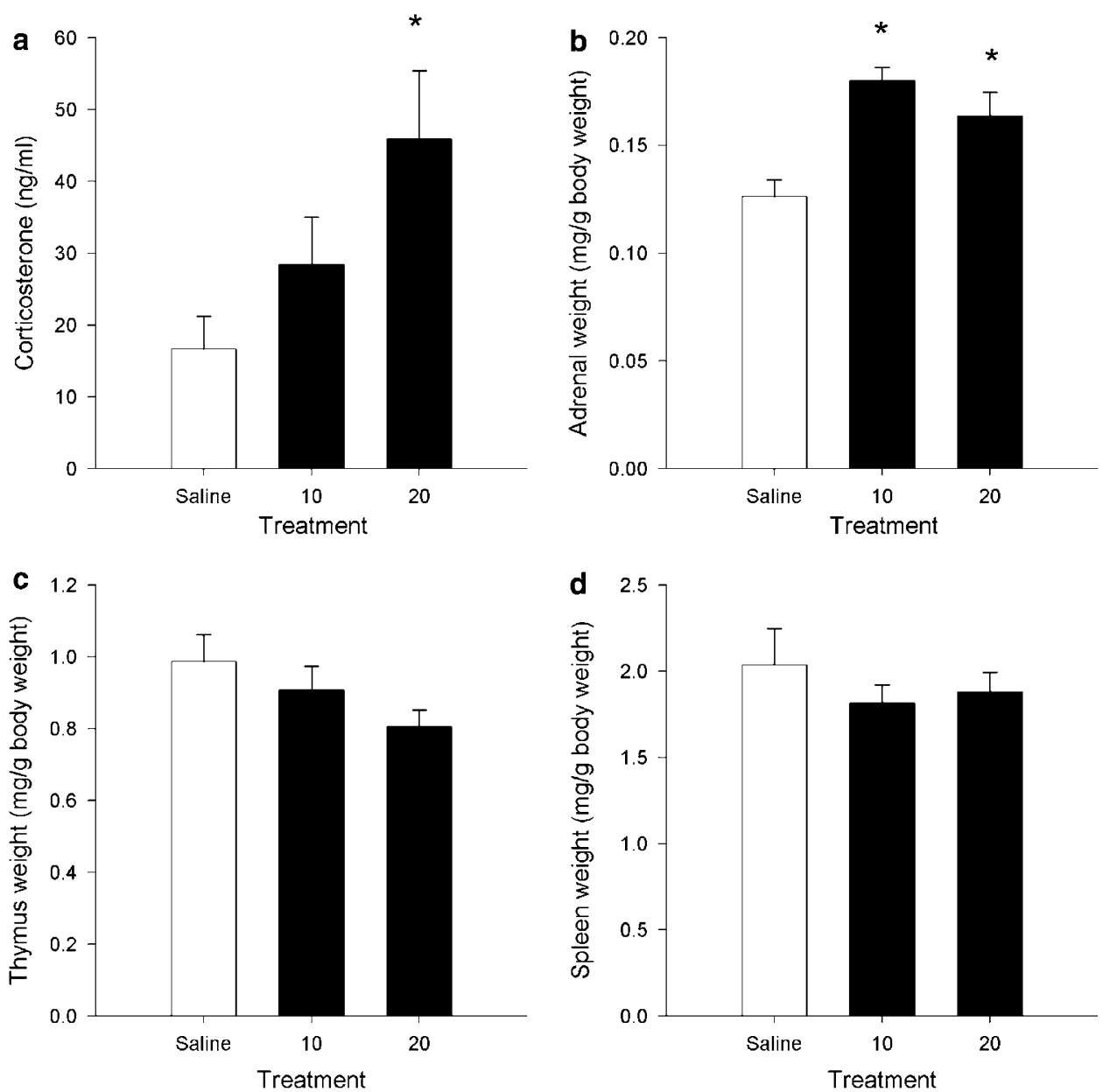

Figure 4 Corticosterone (a), adrenal weights as a percentage of body weights (b), thymus weight as a percentage of body weight (c), and spleen weight as a percentage of body weight (d) are depicted. Plasma and tissue were collected 3 days after 5-MEO-DIPT treatment (Experiment I). Corticosterone levels were increased in animals that received $20 \mathrm{mg} / \mathrm{kg}$ of 5-MEO-DIPT and these animals had heavier adrenal glands. While adrenal weight was greater in the $10 \mathrm{mg} / \mathrm{kg} 5-\mathrm{MEO}-\mathrm{DIPT}$-treated animals, no difference in corticosterone was observed in these animals compared to saline-treated animals. No differences were noted for thymus or spleen. ${ }^{*} p \leqslant 0.05$ vs saline.

Cincinnati water maze. In the CWM, the number of returns to the start position (position ' $\mathrm{B}$ ' as defined by Vorhees (1987)) and number of errors were assessed. For the returns to start, a log $(x+1)$ transformation preceded analysis as the data were not normally distributed. There was a significant Day effect, $\mathrm{F}(6,132)=22.18, p<0.0001$ and an interaction of Treatment $\times$ Day, $F(6,132)=2.51$, $p<0.03$. Examination of Figure 6 a reveals that the animals treated with 5-MEO-DIPT did not return to the start position as often on the first day of testing compared to the saline-treated animals $(p<0.1)$, and had increased returns to start on most other days compared to the saline-treated animals $(p<0.05)$.

Errors of commission were analyzed as a percentage of the errors committed on the first day of testing in order to adjust for the hypoactivity effect observed in spontaneous locomotion. In agreement with the differences in return to start, there was a trend for Treatment to affect the number of errors, $\mathrm{F}(1,22)=3.70, p<0.07$. As seen in Figure $6 \mathrm{~b}$, the animals treated with 5-MEO-DIPT made more errors. There was also a day effect, $\mathrm{F}(6,132)=28.4, p<0.0001$.
Morris water maze. In the MWM, we used path length to represent performance of the animals in this experiment as it has been suggested that this is a more sensitive and accurate measure of performance compared to latency (Lindner, 1997). For acquisition, there was a significant effect of Day, $\mathrm{F}(4,88)=51.52, p<0.0001$; however, as can be seen in Figure 7a, there were no Treatment or Treatment $x$ Day differences. Consistent with this finding, no differences were noted during the acquisition memory (probe trial) phase as well, for latency to the platform location, average distance from platform site, or the number of platform site crossings (Table 2).

Similar to the acquisition data, there were no Treatmentrelated effects during the Reversal phase for path length; all groups displayed learning (Figure $7 \mathrm{~b}$ ), $\mathrm{F}(4,88)=16.18$, $p<0.0001$. During the probe trial, the average distance from the target approached significance, $F(1,22)=3.83$, $p<0.07$. The 5-MEO-DIPT-treated animals tended to be closer to the former platform site, although there were no differences in latency to the site or number of crossings (Table 2). 

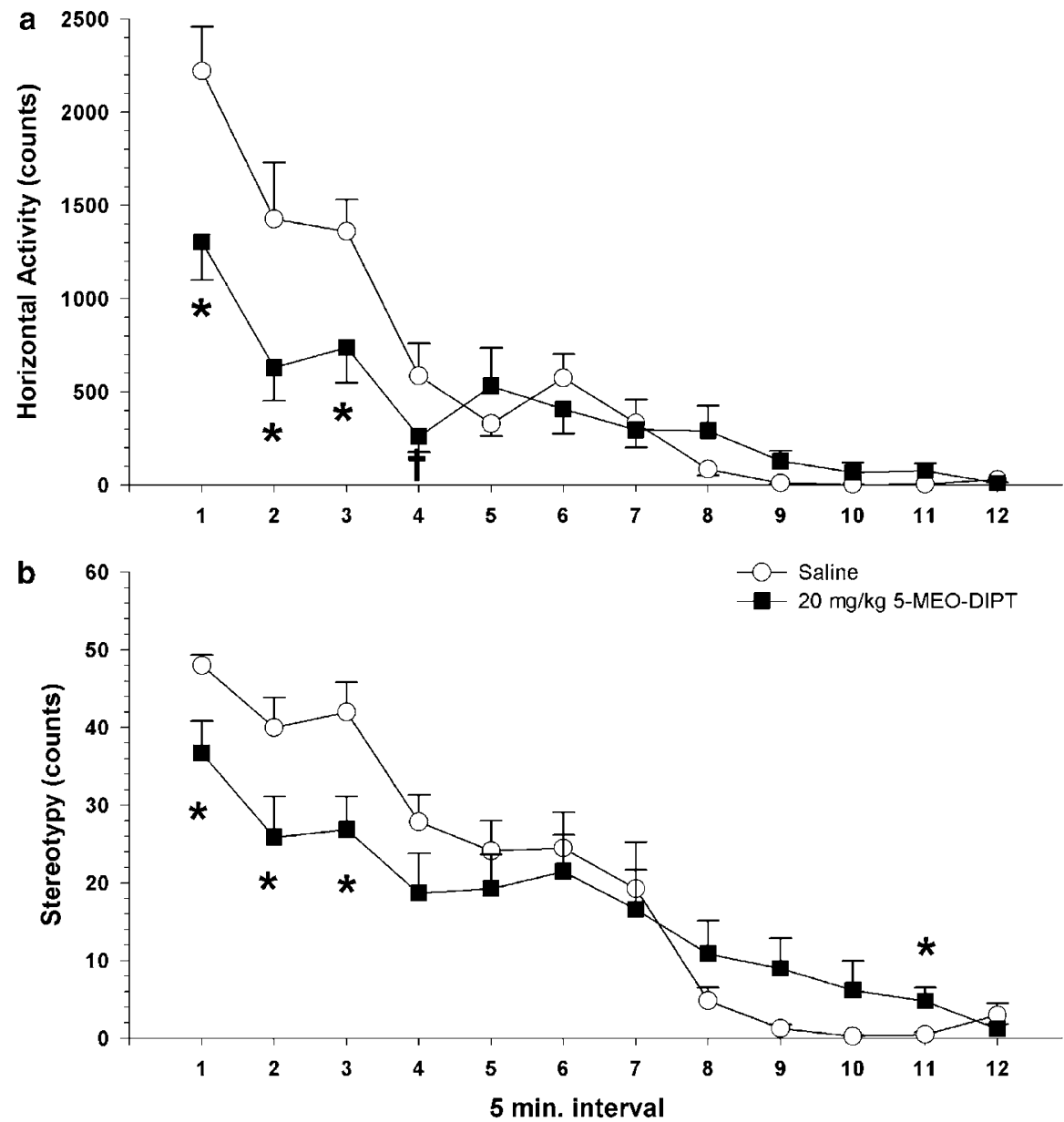

Figure 5 Horizontal activity is shown for animals from Experiment 2 in (a) and stereotypy counts in (b). During the first 15 min (intervals $1-3$ ), animals treated with $20 \mathrm{mg} / \mathrm{kg}$ of 5-MEO-DIPT showed hypoactivity compared to saline-treated animals $(p<0.05)$ for both horizontal activity and stereotypy scores. A trend for reduced levels of horizontal activity was also seen during interval 4 (ie, 16-20 min) and a slight increase in stereotypy was observed at interval I I for the 5-MEO-DIPT-treated animals compared to saline-treated animals. ${ }^{*} p \leqslant 0.05,{ }^{\dagger} p \leqslant 0.1$.

As might be expected following the aforementioned results, during the shift phase, there were no Treatmentrelated changes in learning (Figure 7c) and only the Day effect was significant, $F(4,88)=18.49, p<0.0001$. Again, no differences were noted during the probe trial phase (Table 2). We also tested a delayed probe trial to determine if animals forgot the location of the former target differentially as a result of 5-MEO-DIPT administration. No differences on the delayed probe trial were noted for any of the measures. It should be noted that only 3/12 salineand 2/12 5-MEO-DIPT-treated animals found the location of the platform during the delayed probe trial. A comparison of the average distance from the former platform location with the probe trial administered 1 day after learning showed that there was a large increase in average distance during the delayed probe trial (Table 2).

Novel object and novel place recognition. The novel object test was performed before the novel place test. No differences in novel object were found in regard to the time spent investigating the new object (saline $=20.8 \pm 1.3 \mathrm{~s}$ and 5 -MEO-DIPT $=18.3 \pm 2.5 \mathrm{~s}$ ); however, the animals treated with 5-MEO-DIPT took considerably longer to accumulate $30 \mathrm{~s}$ of object exploration time compared to the saline-treated animals $(t(20)=2.07, p=0.05$ : saline $=$ $127 \pm 22.8 \mathrm{~s}$ and 5 -MEO-DIPT $=275 \pm 62.4 \mathrm{~s}$ ). Similarly, there was no difference between Treatments in exploration of the object placed in a novel location (saline $=16.2 \pm 0.9 \mathrm{~s}$ and 5 -MEO-DIPT $=16.2 \pm 1.3 \mathrm{~s}$ ). In agreement with the longer latencies to accumulate $30 \mathrm{~s}$ of object exploration time, the 5-MEO-DIPT-treated animals again took longer than the saline-treated animals $(t(20)=2.77$, $p<0.02$ : saline $=162.5 \pm 20.2 \mathrm{~s}$ compared to $5-\mathrm{MEO}-\mathrm{DIPT}=$ $286.3 \pm 37.1)$ during novel place testing.

Locomotor activity with challenge. Animals were placed in the locomotor chambers for $30 \mathrm{~min}$ (pre-challenge), removed and given $(+)$-methamphetamine $(1 \mathrm{mg} / \mathrm{kg})$ and the amount of horizontal activity was recorded for another $120 \mathrm{~min}$ (post-challenge) (Figure 8a). No significant differences were noted for Treatment or Treatment $\times$ Interval in either pre- or post-challenge testing. There were significant differences in the amount of activity over Time during both stages, $\mathrm{F}(5,110)=57.82$ and $\mathrm{F}(23,506)=21.4$, respectively, $p<0.0001$. Because we noted differences only during the first $15 \mathrm{~min}$ in the initial locomotor activity test, we did a 
sub-analysis for both the pre- and post-challenge stages over the first three intervals $(15 \mathrm{~min})$. For the pre-challenge stage, the effect of Treatment approached significance, $p<0.09$. For the post-challenge stage, there was a significant effect of Treatment, $\mathrm{F}(1,22)=4.54, p<0.05$. The animals treated with 5-MEO-DIPT were less active during this time period relative to the saline-treated animals. Although the
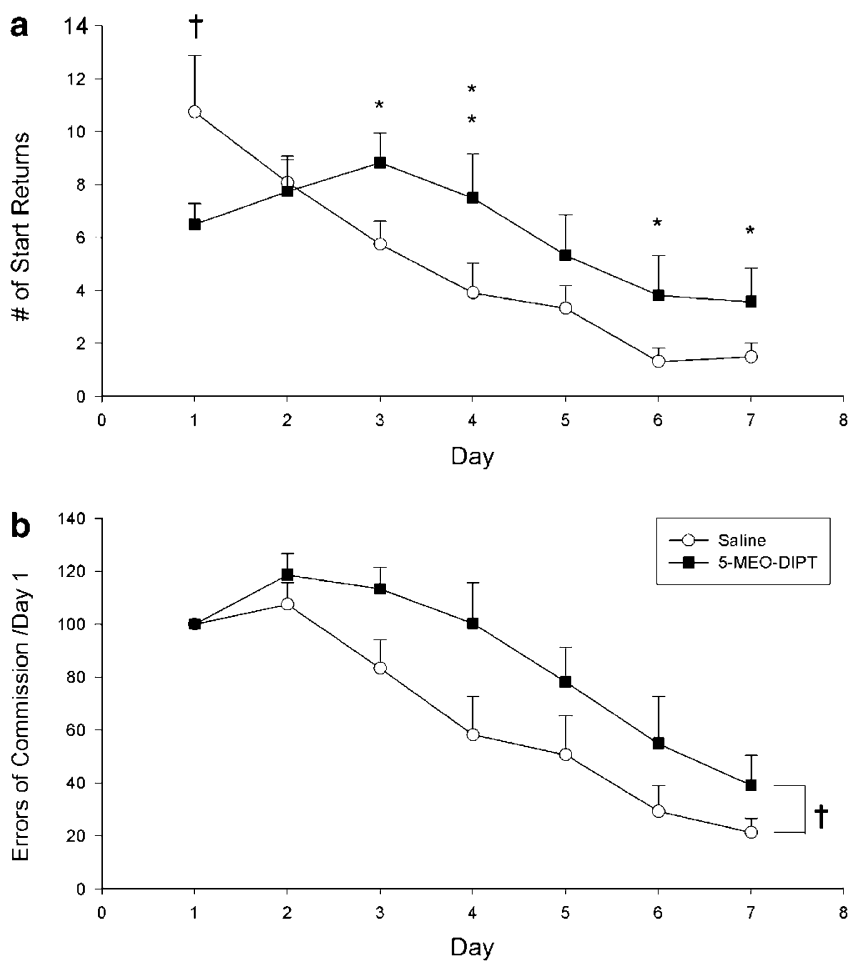

Figure 6 Animals were tested in the CWM following administration of 5-MEO-DIPT beginning I week after administration, and the number of returns to start (a) and number of errors of commission (b) were recorded. For the number of returns to start, there was an interaction of Treatment and Interval, revealing that animals treated with 5-MEO-DIPT had significantly more returns to start on days 3, 4, 6, and 7 and a trend for fewer returns to start on Day I. There was a trend for the number of errors to be increased in the animals treated with 5-MEO-DIPT. ${ }^{*} p \leqslant 0.05$, *** $p \leqslant 0.01,{ }^{\dagger} p \leqslant 0.1$
5-MEO-DIPT-treated animals were less active following (+)-methamphetamine treatment, there were no significant differences in the stereotypy scores between treatments (Figure 8b) and only the main effect of Interval was significant, $\mathrm{F}(23,506)=14.46, p<0.0001$, as would be expected.

Neurotransmitters. In Experiment 2, a Treatment $\times$ Brain Region ANOVA was performed for each neurotransmitter and metabolite. As described in Experiment 1, there were significant regional differences for all neurotransmitters and metabolites, $p<0.0001$. For NE, the Treatment $\times$ Region interaction approached significance, $\mathrm{F}(1,21)=4.07, p<0.06$. This was the result of the 5-MEO-DIPT-treated animals having slightly higher levels of $\mathrm{NE}$ in the hippocampus relative to the saline-treated animals (a $t$-test of just this comparison revealed a significant effect, $p<0.03$ ). No other Treatment or interactions with Treatment were observed for any of the neurotransmitters, metabolites, or the ratio of metabolite and neurotransmitter at this time point (Table 3).

Peripheral measures. All peripheral measures are shown in Table 4 for Experiment 2. Neither corticosterone nor glucose levels in plasma were different between treatments 10 min following the delayed probe trial. Furthermore, no differences were detected in thymus and spleen weight ratios between the Treatments. There was a significant increase in the weight of the adrenal gland in the 5-MEODIPT-treated animals compared to the saline-treated animals, $t(22)=2.08, p<0.05$; however, this effect only approached significance when expressed as a percent of the animal's body weight, $p<0.08$.

\section{DISCUSSION}

This is the first study to characterize the effects of 5-MEODIPT for its potential to induce monoamine, neuroendocrine, and behavioral changes in rats. We demonstrated that 5-MEO-DIPT disrupts path integration learning in the CWM (as indexed by number of returns to start) but does
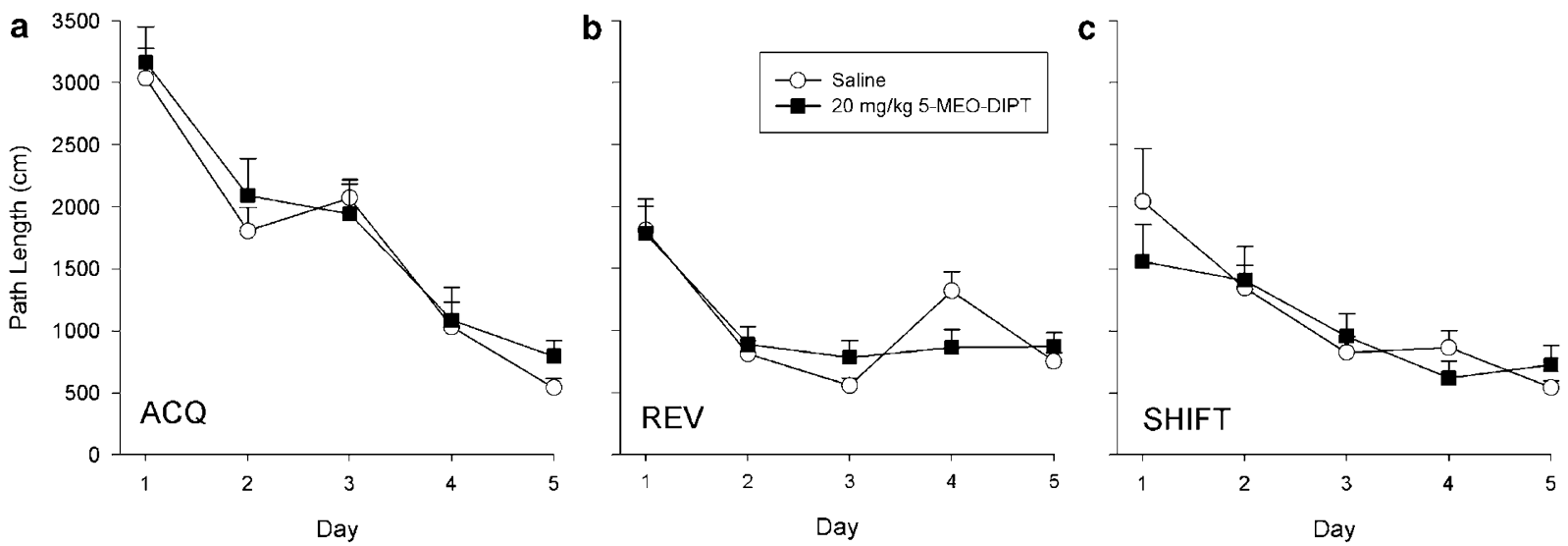

Figure 7 Following the CWM, the MWM was completed for acquisition (ACQ, a), reversal (REV, b), and shifted with reduced platform (SHIFT, c). No differences between treatments were noted in the path length the animals took to get to the platform. As can be seen, regardless of treatment, the distance traveled to get to the platform was reduced over the days of testing. 
Table 2 Probe Trial Performance of Animals from Experiment 2 in the Various Phases of Memory Testing Following 0 or $20 \mathrm{mg} / \mathrm{kg} 5$ MEO-DIPT

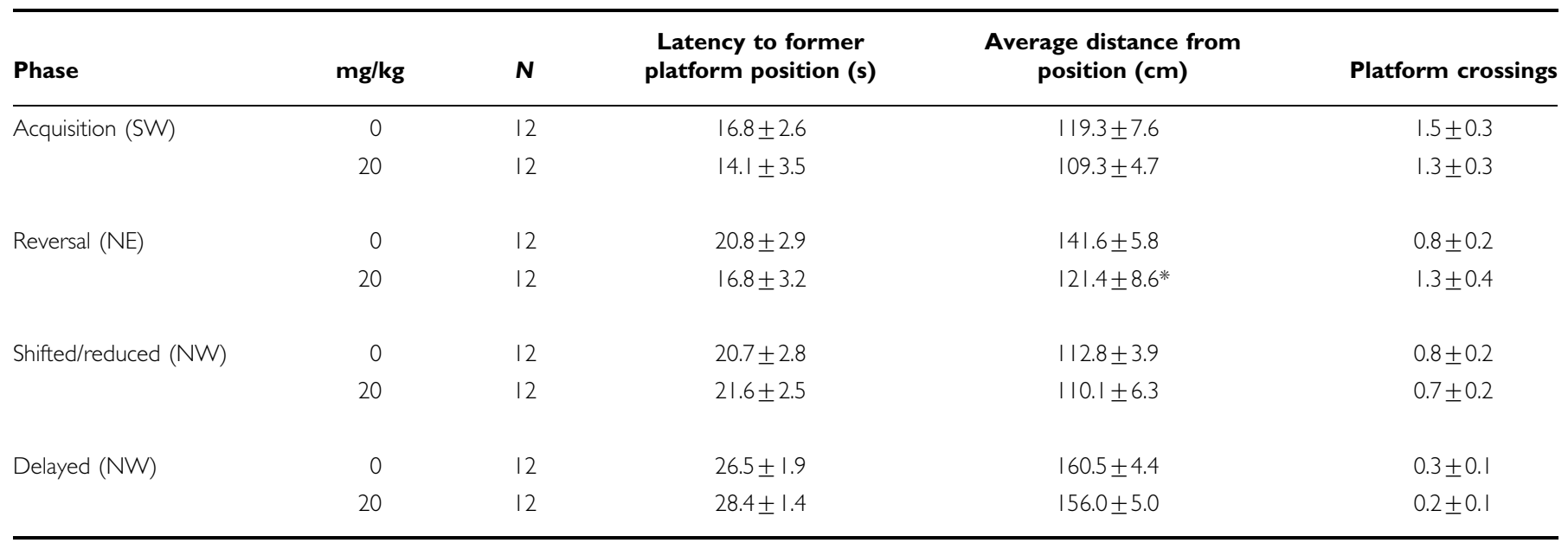

* $p<0.07$.

not alter the ability of the animals to spatially learn in the MWM. Interestingly, the path integration task used in this experiment, the CWM, is more sensitive at detecting detrimental effects of several substituted amphetamines in adult rats than the MWM (Able et al, 2006; Skelton et al, 2004; Williams et al, 2002) and the present results are consistent with that pattern. Comparable to the administration of fenfluramine, a potent 5-HT releaser, 5-MEODIPT (1) produced hypothermia during drug administration, (2) stimulated the adrenal function of the animals as demonstrated by the increased levels of CORT 3 days after drug administration and an increase in adrenal weights, and (3) disrupted CWM performance while sparing MWM performance (cf, Skelton et al, 2004; Williams et al, 2001; Williams et al, 2002). Unlike fenfluramine, 5-MEO-DIPT produced no decrease in 5-HT or 5-HIAA (Skelton et al, 2004). As reported recently, the lack of effect on 5-HT levels may be the result of 5-MEO-DIPT acting directly on various 5-HT receptor subtypes, although if 5-MEO-DIPT binds to the 5-HT transporter is unknown at this time.

While the differences in CORT might suggest a propensity for differences in anxiety, no differences were seen 3 days after 5-MEO-DIPT in the marble burying test; however, there were reductions in the exploration of a novel environment on this day. While reductions in exploration of a novel environment might be attributed to differences in anxiety, the fact that the 5-MEO-DIPT-treated animals did not spend more time in the periphery would suggest that other factors may have been more important for the reduced locomotor levels. Other drugs that stimulate the $5-\mathrm{HT}_{2 \mathrm{C}}$ receptor have been shown to produce hypolocomotion (Gleason et $a l, 2001$ ) as well and as stated above, there is now evidence that 5-MEO-DIPT has some affinity for the $5-\mathrm{HT}_{2 \mathrm{C}}$ receptor (Fantegrossi et al, 2006). One potential confound for the reduced locomotor scores would be if the animals were engaging in stereotypy more than the salinetreated animals, however that was not the case, and in fact the opposite was true during the initial phase of locomotor assessment. Not only were the initial levels of locomotion reduced when the animals were placed in a novel environment, 5-MEO-DIPT treatment also increased the time required to finish the novel object and place recognition tasks. Moreover, the 5-MEO-DIPT-treated animals showed an attenuated response to (+)-methamphetamine challenge. For human users, blunted responses to drugs might increase the perceived need to use larger doses of 5-MEO-DIPT or other drugs.

5-MEO-DIPT at the highest dose induced myoclonic activity in all animals. Although these seizures were selfresolving, they may have induced secondary effects that were detected later as changes in learning or locomotor activity. In this regard, the $10 \mathrm{mg} / \mathrm{kg} 5-\mathrm{MEO}-\mathrm{DIPT}$ group may be instructive in future studies because about $50 \%$ of the animals in this group showed myoclonus and about $50 \%$ did not. Therefore, future studies should compare those animals that displayed seizures with those that did not to determine the impact of the seizure. It is interesting to note that human users have also experienced seizure activity following 5-MEO-DIPT as well as death (Kiyota, 2004; Smolinske et al, 2004; Tanaka et al, 2006). In the current study, only one animal died and this was only after a single drug administration and not when seizure activity was noted for the other animals.

Other drugs of abuse, such as cocaine and (+)methamphetamine have also been shown to produce seizure activity when administered to adult animals (Hanson et al, 1999) and in the case of (+)-methamphetamine, neurotoxicity is induced (Hanson et al, 2004). While it might be suspected that rats exposed to doses of $(+)$-methamphetamine that produce seizures and neurotoxicity would have nonspecific behavioral alterations, the contrary is more apparent. For example, novel object recognition is impaired in animals treated with $(+)$-methamphetamine; however, novel place recognition and spatial learning and memory are intact (Belcher et al, 2005; Bisagno et al, 2002; Friedman et al, 1998; Schroder et al, 2003). It should be noted that Friedman et al (1998) showed that animals treated with (+)-methamphetamine had a small deficit in latency to the platform in the MWM, but this was only apparent on one of the 5 days tested and no differences were noted in the probe phase. One residual effect that neurotoxic doses of $(+)$-methamphetamine administration in adult animals 

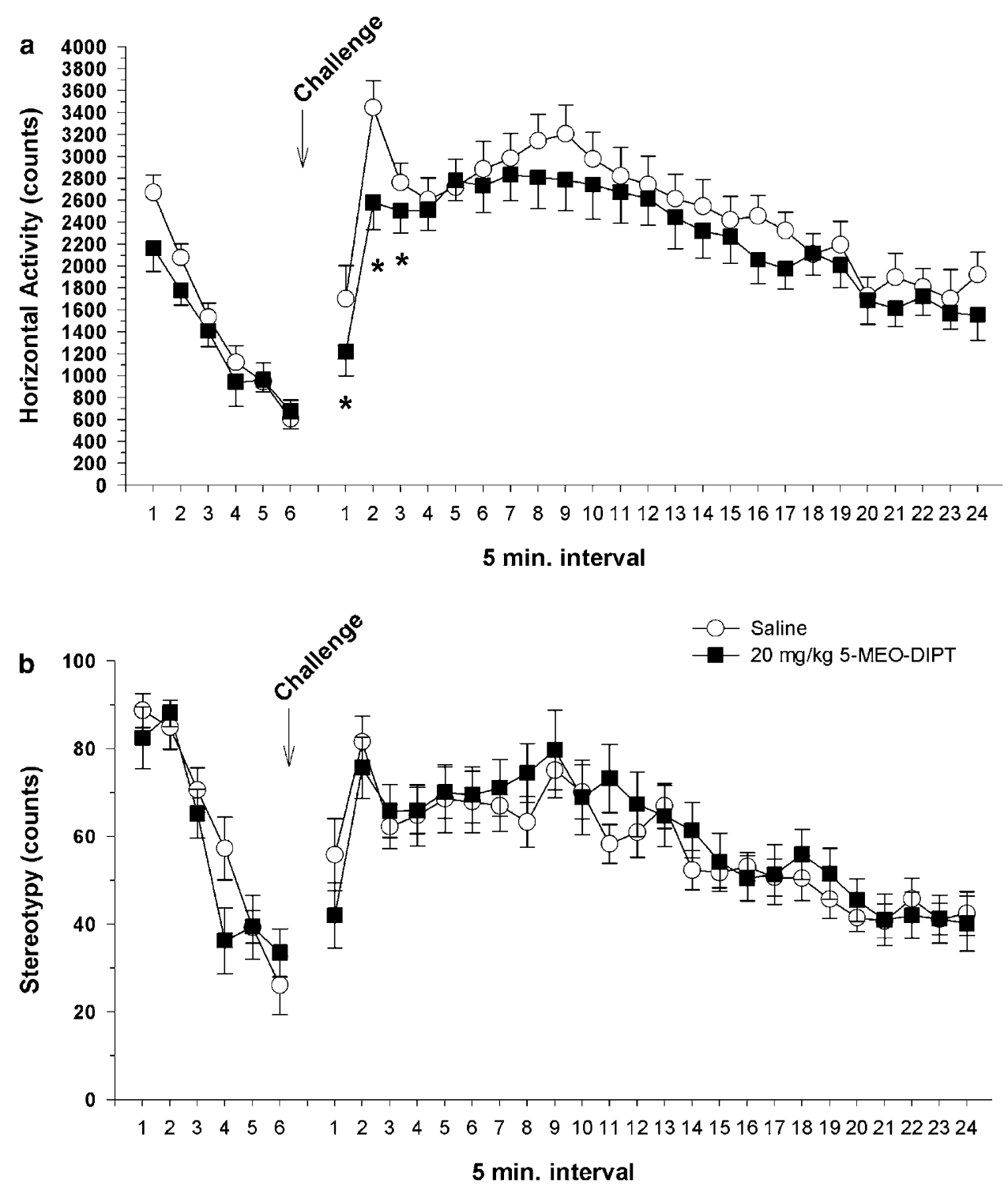

Figure 8 Animals were placed for $30 \mathrm{~min}$ in the locomotor apparatus used previously during the initial assessment of horizontal activity and stereotypy. Following a $30 \mathrm{~min}$ habituation period, animals received methamphetamine (I mg/ $\mathrm{kg}$ ), were replaced back in the apparatus, and horizontal activity (a) and stereotypy scores (b) were recorded for another $120 \mathrm{~min}$. During the first $15 \mathrm{~min}$ of habituation, there was a trend for hypoactivity in the 5-MEO-DIPTtreated animals $(p<0.1)$. There was a significant decrease in horizontal activity following methamphetamine in the 5-MEO-DIPT-treated animals compared to saline-treated animals during the first 15 min of methamphetamine exposure. However, the reduction in horizontal activity was not the result of increased stereotypy in the 5-MEO-DIPT-treated animals as no difference was detected between these animals and the saline-treated animals. $* 2<0.05$.

Table 3 Regional Levels of Neurotransmitters (ng/mg Protein) in Animals from Experiment 2 after Behavioral Testing

\begin{tabular}{lccccccccccc}
\hline Region & mg/kg & N & NE & DA & DOPAC & HVA & DOPAC/DA & HVA/DA & 5-HT & 5-HIAA & 5-HIAA/5-HT \\
\hline Neostriatum & 0 & 11 & $1.73 \pm 0.40$ & $201.97 \pm 9.53$ & $19.49 \pm 1.26$ & $14.18 \pm 0.84$ & $0.097 \pm 0.005$ & $0.071 \pm 0.003$ & $9.41 \pm 0.55$ & $13.88 \pm 0.56$ & $1.50 \pm 0.06$ \\
& 20 & 12 & $1.61 \pm 0.24$ & $199.70 \pm 12.07$ & $17.29 \pm 1.02$ & $13.91 \pm 0.77$ & $0.09 \pm 0.002$ & $0.07 \pm 0.002$ & $9.60 \pm 0.66$ & $14.14 \pm 0.70$ & $1.50 \pm 0.05$ \\
& & & & & & & & & & & \\
Hippocampus & 0 & 12 & $4.27 \pm 0.16$ & $0.23 \pm 0.03$ & $0.06 \pm 0.004$ & $0.07 \pm 0.004$ & $0.29 \pm 0.02$ & $0.27 \pm 0.03$ & $4.69 \pm 0.14$ & $8.79 \pm 0.27$ & $1.88 \pm 0.05$ \\
& 20 & 12 & $4.98 \pm 0.24 *$ & $0.33 \pm 0.08$ & $0.07 \pm 0.009$ & $0.07 \pm 0.006$ & $0.26 \pm 0.02$ & $0.23 \pm 0.03$ & $4.99 \pm 0.15$ & $8.99 \pm 0.27$ & $1.81 \pm 0.05$ \\
\hline
\end{tabular}

$* p<0.05$.

does seem to produce reliably is a reduction in locomotor behavior, but this is likely the result of the reductions in dopamine produced by $(+)$-methamphetamine (Wallace et al, 1999). Taken together, the data suggest that even though seizure activity may be induced during the period of drug administration, there does not appear to be a 
Table 4 Peripheral Measures of Animals 10 min after the Delayed Probe Trial in Experiment 2 Following Administration of 0 or 20 mg/kg 5-MEO-DIPT

\begin{tabular}{|c|c|c|c|c|c|c|}
\hline Treatment & $\begin{array}{c}\text { Corticosterone } \\
(\mathrm{ng} / \mathrm{ml})\end{array}$ & Glucose (mg/dl) & $\begin{array}{c}\text { Adrenal weight } \\
\text { (g) }\end{array}$ & $\begin{array}{l}\text { Adrenal weight } \\
\text { (\% body weight) }\end{array}$ & $\begin{array}{l}\text { Thymus weight } \\
\text { (\% body weight) }\end{array}$ & $\begin{array}{l}\text { Spleen weight } \\
\text { (\% body weight) }\end{array}$ \\
\hline Saline & $144.7 \pm 16.3$ & $98.75 \pm 2.78$ & $0.049 \pm 0.004$ & $0.095 \pm 0.009$ & $0.757 \pm 0.037$ & $1.43 \pm 0.05$ \\
\hline
\end{tabular}

$* p<0.05 ;{ }^{\dagger} p<0.1$.

predictable functional change, with the possible exception of locomotor activity.

Among drug users, 5-MEO-DIPT is sometimes substituted for MDMA or taken in conjunction with it. Although 5-MEO-DIPT was first synthesized almost 30 years ago, its abuse in the US is new and therefore very little is known about its prevalence or long-term effects. The lack of data is not uncommon for drugs that have recently been scheduled by the DEA. For example, while the DEA and other authorities recognized the abuse patterns of MDMA as problematic, prevalence and effect data lagged behind. When MDMA was put on emergency schedule 1 in 1985, it did not have a subcategory in the amphetamine section of the Monitoring the Future survey regarding prevalence of use. Furthermore, questions were not added for MDMA to this survey until 1989 for college age surveys and 1996 for secondary school surveys (Johnston et al, 2005). In Shulgin and Carter's initial human study, users reported effects (ie, hallucinations, etc.) when 5-MEO-DIPT was taken at a dose of 6-10 mg; however from the various case studies and other sources (eg, www.Erowid.com), it is reported that the drug is taken at higher concentrations (up to $100 \mathrm{mg}$ per 'hit') and may be taken multiple times on a single day (Ikeda et al, 2005; Kiyota, 2004).

When administering psychostimulants to animals, several different factors have to be considered when developing a model of human exposure. For example, one must consider the amount obtained in a single use (tablet), the number of tablets taken on any given occasion, the frequency of use per day, drug disposition, metabolites, and the pharmacokinetics of the drug. While it is difficult to directly account for each of these parameters, accounting for some will provide a better model of human use. While administration to rats could be compared on a strict $\mathrm{mg} / \mathrm{kg}$ basis, this likely underestimates the bioavailability of the drug, and therefore scaling methods have been proposed to account for differences in body size, disposition, excretion, metabolic rate, and related factors (Lin, 1998). If one uses the classic Mordenti and Chappell's interspecies scaling formula of Dose $_{\text {human }}=$ Dose $_{\text {animal }}\left(\text { Weight }_{\text {human }} / \text { Weight }_{\text {animal }}\right)^{0.7} \quad($ (Mordenti and Chappell, 1989) and referred to in (Green et al, 2003) for drugs of abuse), and assumes a $60 \mathrm{~kg}$ human, $300 \mathrm{~g}$ rat, and a human dose of $10 \mathrm{mg}$, then a rat would require a dose of $0.25 \mathrm{mg}$ or $0.82 \mathrm{mg} / \mathrm{kg}$. However, higher doses than $10 \mathrm{mg}$ have been reported in humans, therefore a human dose equivalent of $100 \mathrm{mg}$ would be $8.2 \mathrm{mg} / \mathrm{kg}$ for a rat. However, newer models of interspecies scaling suggest that the exponent in the equation should be either $3 / 4$ (West et al, 2002) or 2/3 (White and Seymour, 2005), which would suggest that the $\mathrm{mg} / \mathrm{kg}$ basis for a rat would be between 6.27 and $9.75 \mathrm{mg} / \mathrm{kg}$, respectively. It should be noted that others have warned that the predictive metabolic rate for some drugs using interspecies scaling may not always be accurate (Mahmood, 1999), although this conclusion was based on a small comparative study rather than on a large number of species as in White and Seymour (2005). Another consideration for the animal model is the level of drug in the plasma after drug administration as discussed previously (Cho et al, 2001). No pharmacodynamic data for 5-MEODIPT are currently available; however, most drugs are cleared faster in rats than in humans and therefore an increased number of drug administrations would be required for rats to achieve and maintain the levels observed in humans. In this study, we used 10 (a dose predicted to be close to some human abusers) and $20 \mathrm{mg} / \mathrm{kg}$ (a dose that may represent very heavy users of the drug) of 5-MEO-DIPT. While these doses are predicted to model heavy human users or even overdose situations based on interspecies scaling, dose frequency is probably too low to accurately reflect the human situation. Nevertheless, the present doses are not unreasonable considering there are data for users of 5-MEO-DIPT that show seizure activity can develop (as well as death) (Kiyota, 2004; Smolinske et al, 2004; Tanaka et al, 2006) and other club drugs, such as MDMA or methamphetamine, are known to be abused over a wide range of dosages that can even exceed a gram/day (Cho, 1990; Derlet and Heischober, 1990; Kouimtsidis et al, 2006; Scholey et al, 2004).

The CWM is a test that can assess path integration. Path integration requires that an animal be able to return to a fixed reference point after journeying away from the start without the use of salient environmental landmarks (Etienne and Jeffery, 2004). During the initial learning phase, it is noted that animals will return to the reference point more often compared to after the task is learned. We therefore measured the number of times that an animal returned to the start (the reference point in this maze) since as the animals learn the path the number of returns to the start should diminish. Deficits in path integration were observed for animals receiving 5-MEO-DIPT inasmuch as treated animals showed increased numbers of returns to start. In addition, 5-MEO-DIPT-treated rats showed an increased error trend in the maze. Yet, these same animals showed intact spatial learning ability in the MWM. It has been shown that appropriate spatial learning requires the hippocampus (Morris et al, 1982), and the hippocampus has also been implicated in path integration (Etienne and Jeffery, 2004), although there is still some debate in this regard (Alyan and McNaughton, 1999). Interestingly, if the hippocampus is involved in both path integration and spatial learning, we were unable to show comparable differences between the two treatments in the ability of 
the animals to learn in the two tasks. This discrepancy might be explained by disrupted inputs to the hippocampus during path integration that may not be required for spatial learning when salient cues are present. For example, the parietal cortex, anterior thalamus, mammillary nucleus, dorsal tegmentum, and vestibular nucleus are also suggested to be important for path integration learning (Etienne and Jeffery, 2004); however, for spatial learning it is likely more visual-related regions would be important such as the visual cortex (Hoh et al, 2003). Therefore, any effects of 5-MEO-DIPT in the regions important for path integration may impair the ability of the animals to learn well. How 5-MEO-DIPT might affect these other brain regions is unknown at this time. However, other drugs such as MDMA and fenfluramine, both of which produce deficits in the CWM without spatial learning deficits in the MWM, are known to affect thalamic nuclei and/or parietal cortex as demonstrated by Fluoro-Jade staining (Schmued et al, 1999; Schmued, 2003).

We have previously hypothesized that altered CORT levels may in part mediate the deficits in path integration. The present data show that 5-MEO-DIPT stimulates adrenal function as demonstrated by the increased CORT 3 days after dosing, and the larger adrenal size at the end of behavioral testing. Although the half-life of 5-MEO-DIPT is unknown, it is unlikely that any drug was available when CORT levels were examined 3 days following treatment. The increased adrenal size at the end of behavioral testing also suggests that adrenal function is altered long term in these animals. Taken together with our previous data showing that adrenalectomy or metyrapone treatment abolishes the path integration deficits produced by fenfluramine, the increased levels of CORT and adrenal hypertrophy and thymic involution in this study suggest that CORT may mediate the path integration deficits. Consistent with this, glucocorticoid receptors are present in various brain regions thought to be important for path integration, such as the anterior thalamus and parietal cortex (Morimoto et al, 1996).

While we did not directly determine the potential of 5-MEO-DIPT to induce neurotoxicity, we did demonstrate there were no long-term reductions in monoamines, an effect sometimes associated with psychostimulant-induced neurotoxicity. For example, markers for neurotoxicity are increased and monoamines decreased $72 \mathrm{~h}$ following a single day of multiple methamphetamine administrations (Bowyer et al, 1994; Cappon et al, 1997; O'Callaghan and Miller, 2002; O'Dell and Marshall, 2002). We therefore selected the $72 \mathrm{~h}$ time point for examination of brain regions in this study. Nonetheless, no depletions of monoamines were noted; whether this was related to drug-induced hypothermia, a protective effect with most substituted amphetamines, is not yet known and will require treating animals at different ambient temperatures to resolve. It should be noted, however, that increases in body temperature are not always required for depletions of monoamines as fenfluramine induces hypothermia and depletes serotonin without an increase in GFAP (Miller and O'Callaghan, 1995; O'Callaghan and Miller, 1994; Rowland et al, 1993; Rowland and Carlton, 1986; Skelton et al, 2004; Stewart and Slikker, 1999). The lack of depletions in monoamines and the hypothermia suggest that 5-MEO-DIPT does not induce neurotoxicity to monoaminergic neurons; however, effects on other neurotransmitters are unknown. It is interesting that while no differences in monoamines were observed in these animals, there was reduced spontaneous locomotion, reduced novel object and place exploration, and decreased (+)-methamphetamine-induced hyperactivity. These results suggest that 5 -MEO-DIPT may be altering receptors important in general activity levels or affecting neurons that have influences on locomotion and non-goal-related activity.

The present data are a first step in defining the potential effects of 5-MEO-DIPT. Although it is recognized that an animal model is unable to fully mimic the circumstances under which humans use drugs, such models help to identify potential areas of concern for human health. These data suggest that path integration learning, adrenal cortical output, and motor pathways may all be affected by the use of 5-MEO-DIPT and therefore should serve as a cautionary note to users and health-care personnel.

\section{ACKNOWLEDGEMENTS}

Portions of these data were presented at the 14th annual meeting of the International Behavioral Neuroscience Society meeting (June, 2005) in Santa Fe, NM. This study was supported by National Institutes of Health grants DA014269 (MTW), DA006733 (CVV), and training grant ES07051 (TLS, MRS).

\section{REFERENCES}

Able JA, Gudelsky GA, Vorhees CV, Williams MT (2006). 3,4-Methylenedioxymethamphetamine in adult rats produces deficits in path integration and spatial reference memory. Biol Psychiatry 59: 1219-1226.

Akana SF, Shinsako J, Dallman MF (1983). Drug-induced adrenal hypertrophy provides evidence for reset in the adrenocortical system. Endocrinology 113: 2232-2237.

Alatrash G, Majhail NS, Pile JC (2006). Rhabdomyolysis after ingestion of 'foxy,' a hallucinogenic tryptamine derivative. Mayo Clin Proc 81: 550-551.

Alyan S, McNaughton BL (1999). Hippocampectomized rats are capable of homing by path integration. Behav Neurosci 113: 19-31.

Bakker JM, Kavelaars A, Heijnen CJ, Tilders FJH, van Rees EP (1997). Effects of neonatal dexamethasone treatment on hypothalamo-pituitary-adrenal axis and immune system of the rat. J Neuroimmunol 74: 69-76.

Balcombe JP, Barnard ND, Sandusky C (2004). Laboratory routines cause animal stress. Contemp Top Lab Anim Sci 43: 42-51.

Belcher AM, O'Dell SJ, Marshall JF (2005). Impaired object recognition memory following methamphetamine, but not $\mathrm{p}$ chloroamphetamine- or d-amphetamine-induced neurotoxicity. Neuropsychopharmacology 30: 2026-2034.

Bisagno V, Ferguson D, Luine VN (2002). Short toxic methamphetamine schedule impairs object recognition task in male rats. Brain Res 940: 95-101.

Bowyer JF, Davies DL, Schmued L, Broening HW, Newport GD, Slikker Jr W et al (1994). Further studies of the role of hyperthermia in methamphetamine neurotoxicity. J Pharmacol Exp Therap 268: 1571-1580.

Cappon G, Morford LL, Vorhees CV (1997). Ontogeny of methamphetamine-induced neurotoxicity and associated hyperthermic response. Dev Brain Res 103: 155-162. 
Cho AK (1990). Ice: a new dosage form of an old drug. Science 249: 631-634.

Cho AK, Melega WP, Kuczenski R, Segal DS (2001). Relevance of pharmacokinetic parameters in animal models of methamphetamine abuse. Synapse 39: 161-166.

Clark RE, Zola SM, Squire LR (2000). Impaired recognition memory in rats after damage to the hippocampus. J Neurosci 20: 8853-8860.

Cohen MA, Skelton MR, Schaefer TL, Gudelsky GA, Vorhees CV, Williams MT (2005). Learning and memory after neonatal exposure to 3,4-methylenedioxymethamphetamine (ecstasy) in rats: interaction with exposure in adulthood. Synapse 57: 148-159.

Derlet RW, Heischober B (1990). Methamphetamine: stimulant of the 1990s? West J Med 153: 625-628.

Drug Enforcement Administration (DEA) DoJ (2004). Schedules of controlled substances: placement of alpha-methyltryptamine and 5 -methoxy- $N, N$-diisopropyltryptamine into schedule I of the controlled substances act. Final rule Federal Register 69: 5805058053.

Eckler JR, Chang-Fong J, Rabin RA, Smith C, Teitler M, Glennon RA et al (2003). Behavioral characterization of 2-O-desmethyl and 5-O-desmethyl metabolites of the phenylethylamine hallucinogen DOM. Pharmacol Biochem Behav 75: 845-852.

EMCDDA (2004). Annual Report 2004: The state of the drugs problem in the European Union and Norway, European Monitoring Centre for Drugs and Drug Addiction, Luxembourg.

Etienne AS, Jeffery KJ (2004). Path integration in mammals. Hippocampus 14: 180-192.

Fantegrossi WE, Harrington AW, Kiessel CL, Eckler JR, Rabin RA, Winter JC et al (2006). Hallucinogen-like actions of 5-methoxy$\mathrm{N}, \mathrm{N}$-diisopropyltryptamine in mice and rats. Pharmacol Biochem Behav 83: $122-129$.

Farfel GM, Seiden LS (1995). Role of hypothermia in the mechanism of protection against serotonergic toxicity. II. Experiments with methamphetamine, p-chloroamphetamine, fenfluramine, dizocilpine and dextromethorphan. J Pharmacol Exp Therap 272: 868-875.

Friedman SD, Castaneda E, Hodge GK (1998). Long-term monoamine depletion, differential recovery, and subtle behavioral impairment following methamphetamine-induced neurotoxicity. Pharmacol Biochem Behav 61: 35-44.

Gleason SD, Lucaites VL, Shannon HE, Nelson DL, Leander JD (2001). m-CPP hypolocomotion is selectively antagonized by compounds with high affinity for 5-HT(2C) receptors but not 5HT(2A) or 5-HT(2B) receptors. Behav Pharmacol 12: 613-620.

Glennon RA, Young R, Jacyno JM, Slusher M, Rosecrans JA (1983). DOM-stimulus generalization to LSD and other hallucinogenic indolealkylamines. Eur J Pharmacol 86: 453-459.

Green AR, Mechan AO, Elliott JM, O'Shea E, Colado MI (2003). The pharmacology and clinical pharmacology of 3,4-methylenedioxymethamphetamine (MDMA, 'ecstasy'). Pharmacol Rev 55: 463-508.

Hanson GR, Jensen M, Johnson M, White HS (1999). Distinct features of seizures induced by cocaine and amphetamine analogs. Eur J Pharmacol 377: 167-173.

Hanson GR, Rau KS, Fleckenstein AE (2004). The methamphetamine experience: a NIDA partnership. Neuropharmacology 47(Suppl 1): 92-100.

Hoh TE, Kolb B, Eppel A, Vanderwolf CH, Cain DP (2003). Role of the neocortex in the water maze task in the rat: a detailed behavioral and Golgi-Cox analysis. Behav Brain Res 138: 81-94.

Ikeda A, Sekiguchi K, Fujita K, Yamadera H, Koga Y (2005). 5-methoxy- $n, n$-diisopropyltryptamine-induced flashbacks. Am J Psychiatry 162: 815.

Johnston LD, O'Malley PM, Bachman JG, Schulenberg JE (2004). Monitoring the Future National Survey Results on Drug Abuse, 1975-2003. Vol. II College Students and Adult Ages 19-45 (NIH
Publication No. 04-5508). National Institute on Drug Abuse: Bethesda, MD.

Johnston LD, O'Malley PM, Bachman JG, Schulenberg JE (2005). Monitoring the Future National Survey Results on Drug Abuse, 1975-2004. Vol. I Secondary School Students (NIH Publication No. 05-5727). National Institute on Drug Abuse: Bethesda, MD.

Kioukia-Fougia N, Antoniou K, Bekris S, Liapi C, Christofidis I, Padadopoulou-Daifoti Z (2002). The effects of stress exposure on the hypothalamic-pituitary-adrenal axis, thymus, thyroid hormones and glucose levels. Prog Neuropsychopharmacol Biol Psychiatry 26: 823-830.

Kirk RE (1995). Experimental Design: Procedures for the Behavioral Sciences. Brooks/Cole Publishing Co: Pacific Grove.

Kiyota K (2004). Latest cases of acute poisoning in clinical practice-5MeO-DIPT and GHB precursor. Chudoku Kenkyu 17: 259-266.

Koprich JB, Campbell NG, Lipton JW (2003). Neonatal 3,4methylenedioxymethamphetamine (ecstasy) alters dopamine and serotonin neurochemistry and increases brain-derived neurotrophic factor in the forebrain and brainstem of the rat. Brain Res Dev Brain Res 147: 177-182.

Kouimtsidis C, Schifano F, Sharp T, Ford L, Robinson J, Magee C (2006). Neurological and psychopathological sequelae associated with a lifetime intake of 40,000 ecstasy tablets. Psychosomatics 47: $86-87$

Lin JH (1998). Applications and limitations of interspecies scaling and in vitro extrapolation in pharmacokinetics. Drug Metab Dispos 26: 1202-1212.

Lindner MD (1997). Reliability, distribution, and validity of agerelated cognitive deficits in the Morris water maze. Neurobiol Learn Mem 68: 203-220.

Mahmood I (1999). Prediction of clearance, volume of distribution and half-life by allometric scaling and by use of plasma concentrations predicted from pharmacokinetic constants: a comparative study. J Pharm Pharmacol 51: 905-910.

Meatherall R, Sharma P (2003). Foxy, a designer tryptamine hallucinogen. J Anal Toxicol 27: 313-317.

Miller DB, O'Callaghan JP (1995). The role of temperature, stress, and other factors in the neurotoxicity of the substituted amphetamines 3,4-methylenedioxymethamphetamine and fenfluramine. Mol Neurobiol 11: 177-192.

Mordenti J, Chappell W (1989). The use of interspecies scaling in toxicokinetics. In: Yacobi A, Kelly J, Batra V (eds). Toxicokinetics in New Drug Development. Pergamon Press: New York. pp. 42-96.

Morimoto M, Morita N, Ozawa H, Yokoyama K, Kawata M (1996). Distribution of glucocorticoid receptor immunoreactivity and mRNA in the rat brain: an immunohistochemical and in situ hybridization study. Neurosci Res 26: 235-269.

Morris RGM, Garrud P, Rawlins JNP, O’Keefe J (1982). Place navigation impaired in rats with hippocampal lesions. Nature 297: 681-683.

Muller AA (2004). New drugs of abuse update: Foxy Methoxy. J Emerg Nurs 30: 507-508.

Njung'e K, Handley SL (1991). Evaluation of marble-burying behavior as a model of anxiety. Pharmacol Biochem Behav 38: 63-67.

O'Callaghan JP, Miller DB (1994). Neurotoxicity profiles of substituted amphetamines in the C57BL/6J mouse. J Pharmacol Exp Therap 270: 741-751.

O'Callaghan JP, Miller DB (2002). Neurotoxic effects of substituted amphetamines in mice and rats: Challenges to the current dogma. In: Massaro EJ (ed). Handbook of Neurotoxicity. Humana Press: Totowa, NJ. pp. 269-301.

O'Dell SJ, Marshall JF (2002). Effects of vibrissae removal on methamphetamine-induced damage to rat somatosensory cortical neurons. Synapse 43: 122-130. 
Rowland NE, Carlton J (1986). Neurobiology of an anorectic drug: Fenfluramine. Prog Neurobiol 27: 13-62.

Rowland NE, Kalehua AN, Li B-H, Semple-Rowland SL, Streit WJ (1993). Loss of serotonin uptake sites and immunoreactivity in rat cortex after dexfenfluramine occur without parallel glial cell reactions. Brain Res 624: 35-43.

Schmued LC (2003). Demonstration and localization of neuronal degeneration in the rat forebrain following a single exposure to MDMA. Brain Res 974: 127-133.

Schmued L, Slikker W, Clausing P, Bowyer J (1999). dFenfluramine produces neuronal degeneration in localized regions of the cortex, thalamus, and cerebellum of the rat. Toxicol Sci 48: 100-106.

Scholey AB, Parrott AC, Buchanan T, Heffernan TM, Ling J, Rodgers J (2004). Increased intensity of Ecstasy and polydrug usage in the more experienced recreational Ecstasy/MDMA users: a WWW study. Addict Behav 29: 743-752.

Schroder N, O'Dell SJ, Marshall JF (2003). Neurotoxic methamphetamine regimen severely impairs recognition memory in rats. Synapse 49: 89-96.

Selye H (1936). A syndrome produced by diverse nocuous agents. Nature 138: 32.

Shulgin AT, Carter MF (1980). N,N-diisopropyltryptamine (DIPT) and 5-methoxy- $N, N$-diisopropyltryptamine (5-MeO-DIPT). Two orally active tryptamine analogs with CNS activity. Commun Psychopharmacol 4: 363-369.

Skelton MR, Blankenmeyer TL, Gudelsky GA, Brown-Strittholt CA, Vorhees CV, Williams MT (2004). Metyrapone attenuates the sequential learning deficits but not monoamine depletions following d,l-fenfluramine administration to adult rats. Synapse 54: $214-222$.

Smolinske SC, Rastogi R, Schenkel S (2004). Foxy methoxy: a new drug of abuse. Internet J Med Toxicol 7: 3.

Stewart CW, Slikker Jr W (1999). Hyperthermia-enhanced serotonin (5-HT) depletion resulting from D-fenfluramine (DFen) exposure does not evoke a glial-cell response in the central nervous system of rats. Brain Res 839: 279-282.

Tanaka E, Kamata T, Katagi M, Tsuchihashi H, Honda K (2006). A fatal poisoning with 5-methoxy- $N, N$-diisopropyltryptamine, Foxy. Forensic Sci Int 163: 152-154.
US Drug Enforcement Administration (2003). Notice of intent to place alpha-methyltryptamine and 5-methoxy- $N, N$-diisopropyltryptamine into Schedule I. Microgram Bull 36: 41-43.

Vorhees CV (1987). Maze learning in rats: a comparison of performance in two water mazes in progeny prenatally exposed to different doses of phenytoin. Neurotoxicol Teratol 9: 235-241.

Wallace TL, Gudelsky GA, Vorhees CV (1999). Methamphetamineinduced neurotoxicity alters locomotor activity, stereotypic behavior, and stimulated dopamine release in the rat. J Neurosci 19: 9141-9148.

West GB, Woodruff WH, Brown JH (2002). Allometric scaling of metabolic rate from molecules and mitochondria to cells and mammals. Proc Natl Acad Sci USA 99(Suppl 1): 2473-2478.

White CR, Seymour RS (2005). Sample size and mass range effects on the allometric exponent of basal metabolic rate. Comp Biochem Physiol A Mol Integr Physiol 142: 74-78.

Williams MT, Moran MS, Vorhees CV (2003a). Refining the critical period for methamphetamine-induced spatial deficits in the Morris water maze. Psychopharmacology 168: 329-338.

Williams MT, Morford LL, McCrea AE, Inman-Wood SL, Vorhees CV (2001). Elevations in plasmatic titers of corticosterone and aldosterone, in the absence of changes in ACTH, testosterone, or glial fibrillary acidic protein, $72 \mathrm{~h}$ following d,l-fenfluramine or d-fenfluramine administration to rats. Neurotoxicol Teratol 23: 23-32.

Williams MT, Morford LL, McCrea AE, Wood SL, Vorhees CV (2002). Administration of d,l-fenfluramine to rats produces learning deficits in the Cincinnati water maze but not the Morris water maze: relationship to adrenal cortical output. Neurotoxicol Teratol 24: 783-796.

Williams MT, Morford LL, Wood SL, Wallace TL, Fukumura M, Broening HW et al (2003b). Developmental d-methamphetamine treatment selectively induces spatial navigation impairments in reference memory in the Morris water maze while sparing working memory. Synapse 48: 138-148.

Wilson JM, McGeorge F, Smolinske S, Meatherall R (2005). A foxy intoxication. Forensic Sci Int 148: 31-36. 